\title{
ПРАКТИЧЕСКИЕ РЕКОМЕНДАЦИИ ПО ЛЕКАРСТВЕННОМУ ЛЕЧЕНИЮ РАКА МОЛОЧНОЙ ЖЕЛЕЗЫ
}

Коллектив авторов: Стенина М.Б., Жукова Л.Г., Королева И.А., Пароконная А.А., Семиглазова Т.Ю., Тюляндин С.А., Фролова М.А.

DOI: $10.18027 / 2224-5057-2020-10-3 s 2-09$

Ключевые слова: рак молочной железы, химиотерапия, гормонотерапия, рецепторы эстрогенов и прогестерона, мутация BRCA, Ki67, HER2

При планировании и проведении лекарственной терапии следует руководствоваться стремлением обеспечить всех больных максимально качественным и экономически доступным лечением. Лечение должно планироваться при участии нескольких специалистов, включая врача-хирурга, врача-онколога (химиотерапевта) и врача-радиотерапевта, а также по возможности патоморфолога, что позволит наилучшим образом сочетать локальные и системные методы терапии. Больные должны быть информированы о плане лечебно-диагностических мероприятий, целях различных видов помощи, возможных побочных эффектах и влиянии на функциональную, эмоциональную и социальную сферы. При невозможности проведения рекомендованных методов лечения (наличие противопоказаний) необходимо составить индивидуальный план лечения. Общими противопоказаниями являются случаи тяжелых соматических заболеваний в стадии декомпенсации, когда риск возможных осложнений для жизни в процессе лечения выше риска прогрессирования РМж.

\section{1. ОПРЕДЕЛЕНИЕ СТАДИИ}

Для стадирования РМЖ следует использовать TNM-классификацию АЈСС (8-ое издание, 2017 г.). Выделяют клиническую и патоморфологическую стадии РМЖ, которые могут существенно различаться. Клиническое стадирование (обозначается префиксом «с», от англ. «сlinical») проводится на основании результатов клинического обследования, патоморфологическое (определяется префиксом «р», от англ. «pathologic») - на основании заключения морфолога после изучения удаленных во время операции тканей. Патоморфологическое стадирование по значимости превосходит клиническое. Категории Т и N,

Цитирование: Стенина М.Б., Жукова Л.Г., Королева И.А., Пароконная А.А., Семиглазова Т.Ю., Тюляндин С.А. и соавт. Практические рекомендации по лекарственному лечению рака молочной железы. Злокачественные опухоли: Практические рекомендации RUSSCO \#3s2, 2020 (том 10).09 
оцениваемые после неоадъювантной терапии, обозначаются префиксом «у»: «ус» - при клиническом стадировании или «ур» - при патоморфологическом стадировании, например, «урТ»или «урN».

\section{1. Клинико-патологическая классификация}

\subsection{1. Первичная опухоль (Т) - клиническая и патологическая классификация}

\begin{tabular}{|c|c|c|}
\hline Категории Т & \multicolumn{2}{|c|}{ Критерии Т } \\
\hline Tx & \multicolumn{2}{|c|}{ Недостаточно данных для оценки опухоли } \\
\hline TO & \multicolumn{2}{|c|}{ Нет признаков первичной опухоли } \\
\hline Tis (DCIS) & \multicolumn{2}{|c|}{ Протоковая карцинома in situ } \\
\hline Tis (Педжета) & \multicolumn{2}{|r|}{$\begin{array}{l}\text { Рак Педжета (соска), не ассоциированный с инвазивным раком и/или раком in situ (DCIS) под- } \\
\text { лежащей паренхимы молочной железы. Опухоль паренхимы молочной железы, ассоцииро- } \\
\text { ванную с раком Педжета, следует классифицировать на основании ее размеров и характери- } \\
\text { стик; присутствие рака Педжета в этом случае обязательно должно быть зафиксировано }\end{array}$} \\
\hline \multirow[t]{5}{*}{ T1 } & \multicolumn{2}{|c|}{ Опухоль $\leq 20$ мм в наибольшем измерении } \\
\hline & $\mathrm{T} 1_{\text {mic }}$ & Микроинвазия $\leq 1$ мм в наибольшем измерении \\
\hline & T1a & Опухоль > 1 мм, но $\leq 5$ мм в наибольшем измерении \\
\hline & $\mathrm{T} 1 \mathrm{~B}$ & Опухоль > 5 мм, но $\leq 10$ мм в наибольшем измерении \\
\hline & T1c & Опухоль > 10 мм, но $\leq 20$ мм в наибольшем измерении \\
\hline $\mathrm{T} 2$ & \multicolumn{2}{|c|}{ Опухоль > 20 мм, но $\leq 50$ мм в наибольшем измерении } \\
\hline T3 & \multicolumn{2}{|c|}{ Опухоль > 50 мм в наибольшем измерении } \\
\hline \multirow[t]{5}{*}{ T4 } & \multicolumn{2}{|r|}{$\begin{array}{l}\text { Опухоль любого размера с прямым распространением на грудную стенку и/или кожу } \\
\text { (изъязвление или макроскопические узелки); изолированная инвазия дермы не классифи- } \\
\text { цируется как Т4 }{ }^{1}\end{array}$} \\
\hline & $\mathrm{T} 4 \mathrm{a}$ & $\begin{array}{l}\text { Распространение на грудную стенку; инвазия или тесное прилегание к грудным } \\
\text { мышцам в отсутствие вовлечения в процесс элементов грудной стенки не класси- } \\
\text { фицируется как T4а }\end{array}$ \\
\hline & $\mathrm{T} 4 \mathrm{~b}$ & $\begin{array}{l}\text { Изъязвление и/или ипсилатеральные макроскопические сателлитные узелки } \\
\text { и/или отек кожи (включая положительный симптом «апельсиновой корочки»), } \\
\text { который не соответствует критериям воспалительного рака }\end{array}$ \\
\hline & $\mathrm{T} 4 \mathrm{c}$ & Признаки Т4а и Т4b \\
\hline & T4d & Воспалительный рак \\
\hline
\end{tabular}

1 Грудная стенка включает ребра, межреберные мышцы, переднюю зубчатую мышцу и не включает грудные мышцы.

\subsection{2. Регионарные лимфатические узлы (N)}

\subsubsection{1. Клиническая классификация (cN) ${ }^{1}$}

\begin{tabular}{|l|l|}
\hline Категории сN & Критерии сN \\
\hline сNx & Состояние регионарных лимфатических узлов не может быть оценено (удалены ранее) \\
\hline сNO & $\begin{array}{l}\text { Нет признаков поражения метастазами регионарных лимфатических узлов по данным } \\
\text { клинического осмотра и обследования }\end{array}$ \\
\hline
\end{tabular}




\begin{tabular}{|c|c|c|}
\hline Категории сN & \multicolumn{2}{|c|}{ Критерии сN } \\
\hline \multirow[t]{2}{*}{ cN1 } & \multicolumn{2}{|r|}{$\begin{array}{l}\text { Метастазы в смещаемых ипсилатеральных подмышечных лимфатических узлах I, II } \\
\text { уровней }\end{array}$} \\
\hline & cN1mi & $\begin{array}{l}\text { Микрометастазы (комплексы около } 200 \text { клеток с наибольшим размером более } \\
\text { 0,2 мм, но менее } 2 \text { мм) }\end{array}$ \\
\hline \multirow[t]{3}{*}{ cN2 } & \multicolumn{2}{|r|}{$\begin{array}{l}\text { Метастазы в ипсилатеральных подмышечных лимфатических узлах I, II уровней, } \\
\text { спаянные между собой или фиксированные к близлежащим структурам, или метастазы } \\
\text { в ипсилатеральных внутренних маммарных (парастернальных) лимфатических узлах } \\
\text { в отсутствие клинически явного поражения подмышечных лимфатических узлов }\end{array}$} \\
\hline & $\mathrm{cN} 2 \mathrm{a}$ & $\begin{array}{l}\text { Метастазы в ипсилатеральных подмышечных лимфатических узлах I, II уров- } \\
\text { ней, спаянные между собой или фиксированные к близлежащим структурам }\end{array}$ \\
\hline & $\mathrm{cN} 2 \mathrm{~b}$ & $\begin{array}{l}\text { Метастазы в ипсилатеральных внутренних маммарных (парастернальных) } \\
\text { лимфатических узлах в отсутствие клинически явного поражения подмышеч- } \\
\text { ных лимфатических узлов }\end{array}$ \\
\hline \multirow[t]{4}{*}{ cN3 } & \multicolumn{2}{|r|}{$\begin{array}{l}\text { Метастазы в ипсилатеральных подключичных (III уровень) лимфатических узлах в соче- } \\
\text { тании или без вовлечения подмышечных лимфатических узлов (I, II уровни) } \\
\text { или метастазы в ипсилатеральных внутренних маммарных (парастернальных) лимфати- } \\
\text { ческих узлах и подмышечных лимфатических узлах (I, II уровни) } \\
\text { или метастазы в ипсилатеральных надключичных лимфатических узлах (независимо от со- } \\
\text { стояния подмышечных и внутренних маммарных (парастернальных) лимфатических узлов) }\end{array}$} \\
\hline & cN3a & $\begin{array}{l}\text { Метастазы в ипсилатеральных подключичных (III уровень) лимфатических } \\
\text { узлах }\end{array}$ \\
\hline & cN3b & $\begin{array}{l}\text { Метастазы в ипсилатеральных внутренних маммарных (парастернальных) } \\
\text { лимфатических узлах и подмышечных лимфатических узлах (I, II уровни) }\end{array}$ \\
\hline & $\mathrm{cN} 3 \mathrm{c}$ & Метастазы в ипсилатеральных надключичных лимфатических узлах \\
\hline
\end{tabular}

1 Индексы (sn) или (f) должны быть добавлены к категории N для обозначения способа подтверждения метастатического поражения лимфоузлов - с помощью БСлУ (sn) или тонкогоигольной аспирационной/core-бuoncuи (f).

\subsubsection{2. Патологическая классификация (pN) ${ }^{1}$}

\begin{tabular}{|c|c|c|}
\hline $\begin{array}{l}\text { Категории } \\
\text { pN }\end{array}$ & \multicolumn{2}{|c|}{ Критерии pN } \\
\hline $\mathrm{pNx}$ & \multicolumn{2}{|r|}{$\begin{array}{l}\text { Состояние лимфатических узлов не может быть оценено (не удалены для патологического } \\
\text { исследования или удалены ранее) }\end{array}$} \\
\hline \multirow[t]{3}{*}{ pNO } & \multicolumn{2}{|r|}{$\begin{array}{l}\text { Метастазы в регионарных лимфатических узлах отсутствуют или имеются только изолирован- } \\
\text { ные опухолевые клетки }\end{array}$} \\
\hline & pNO (i+) & $\begin{array}{l}\text { Только изолированные опухолевые клетки (скопления опухолевых клеток не более } \\
\text { 0,2 мм в наибольшем измерении) в лимфатических узлах }\end{array}$ \\
\hline & $\begin{array}{l}\text { pNO } \\
(\mathrm{mol}+)\end{array}$ & $\begin{array}{l}\text { Позитивный молекулярный ПЦР тест; изолированные опухолевые клетки не } \\
\text { определяются }\end{array}$ \\
\hline
\end{tabular}




\begin{tabular}{|c|c|c|}
\hline $\begin{array}{l}\text { Категории } \\
\text { pN }\end{array}$ & \multicolumn{2}{|c|}{ Критерии рN } \\
\hline \multirow[t]{5}{*}{ pN1 } & \multicolumn{2}{|r|}{$\begin{array}{l}\text { Микрометастазы или метастазы в 1-3 подмышечных лимфатических узлах и/или микро- или } \\
\text { макрометастазы в клинически негативных внутренних маммарных (парастернальных) лимфа- } \\
\text { тических узлах, выявленные с помощью БСлу }\end{array}$} \\
\hline & pN1mi & $\begin{array}{l}\text { Микрометастазы (скопления около } 200 \text { клеток более 0,2 мм, но менее 2,0 мм в наи- } \\
\text { большем измерении) }\end{array}$ \\
\hline & pN1a & $\begin{array}{l}\text { Метастазы в 1-3 подмышечных лимфатических узлах, один из которых более } \\
\text { 2,0 мм в наибольшем измерении }\end{array}$ \\
\hline & pN1b & $\begin{array}{l}\text { Метастазы в ипсилатеральных внутренних маммарных (парастернальных) сенти- } \\
\text { нальных лимфоузлах, исключая изолированные опухолевые клетки }\end{array}$ \\
\hline & $\mathrm{pN} 1 \mathrm{c}$ & Признаки pN1a и pN1b \\
\hline \multirow[t]{3}{*}{ pN2 } & \multicolumn{2}{|c|}{$\begin{array}{l}\text { Метастазы в 4-9 подмышечных лимфатических узлах или клинически определяемое пораже- } \\
\text { ние ипсилатеральных внутренних маммарных (парастернальных) лимфатических узлов при } \\
\text { отсутствии поражения подмышечных лимфатических узлов }\end{array}$} \\
\hline & $\mathrm{pN} 2 \mathrm{a}$ & $\begin{array}{l}\text { Метастазы в 4-9 подмышечных лимфатических узлах (как минимум одно скопле- } \\
\text { ние опухолевых клеток } \geq 2 \text { мм) }\end{array}$ \\
\hline & $\mathrm{pN} 2 \mathrm{~b}$ & $\begin{array}{l}\text { Клинически определяемое поражение ипсилатеральных внутренних маммарных } \\
\text { (парастернальных) лимфатических узлов (土 микроскопическое подтверждение) при } \\
\text { отсутствии поражения подмышечных лимфатических узлов }\end{array}$ \\
\hline \multirow[t]{4}{*}{ pN3 } & \multicolumn{2}{|c|}{$\begin{array}{l}\text { Метастазы в } 10 \text { и более подмышечных лимфоузлах } \\
\text { или подключичных (III уровень) лимфатических узлах } \\
\text { или клинически определяемое поражение ипсилатеральных внутренних маммарных (пара- } \\
\text { стернальных) и подмышечных лимфатических узлов (I, II уровни) } \\
\text { или поражение } 4 \text { и более подмышечных лимфатических узлов в сочетании с микро- или } \\
\text { макроскопическим поражением по данным БСлу ипсилатеральных клинически интактных } \\
\text { внутренних маммарных (парастернальных) лимфатических узлов } \\
\text { или поражение ипсилатеральных надключичных лимфатических узлов }\end{array}$} \\
\hline & $\mathrm{pN} 3 \mathrm{a}$ & $\begin{array}{l}\text { Метастазы в } 10 \text { и более подмышечных лимфоузлах } \\
\text { или подключичных (III уровень) лимфатических узлах }\end{array}$ \\
\hline & $\mathrm{pN} 3 \mathrm{~b}$ & $\begin{array}{l}\text { pN1a или pN2a в сочетании с cN2b (клинически определяемым поражением вну- } \\
\text { тренних маммарных (парастернальных) лимфоузлов) } \\
\text { или рN2a в сочетании с pN1b }\end{array}$ \\
\hline & pN3c & Метастазы в ипсилатеральных надключичных лимфоузлах \\
\hline
\end{tabular}

1 Индексы (sn) или (f) должны быть добавлены к категории $N$ для обозначения способа подтверждения метастатического поражения лимфоузлов - с помощью БСлу (sn) или тонкогоигольной аспирационной/core-биопсии (f) соответственно (без последующего удаления лимфоузлов).

\subsection{3. Отдаленные метастазы (М)}

\begin{tabular}{|l|l|l|}
\hline Категории M & \multicolumn{2}{|l|}{ Критерии M } \\
\hline см01 & \multicolumn{2}{|l|}{ Нет клинических или радиографических признаков отдаленных метастазов } \\
\cline { 2 - 3 } & сM0 (i+) & $\begin{array}{l}\text { Нет клинических или радиографических признаков отдаленных метастазов } \\
\text { в сочетании с наличием опухолевых клеток или комплексов опухолевых клеток } \\
\text { размером не более 0,2 мм, определяемых микроскопически или с помощью } \\
\text { молекулярных технологий в крови, костном мозге или иных не регионарных } \\
\text { тканях при отсутствии клинических симптомов или признаков метастазов }\end{array}$ \\
\hline
\end{tabular}




\begin{tabular}{|l|l|}
\hline Категории M & Критерии M \\
\hline сM1 & $\begin{array}{l}\text { Есть отдаленные метастазы, определяемые клинически или с помощью методов визуа- } \\
\text { лизации }\end{array}$ \\
\hline рM1 & $\begin{array}{l}\text { Любой гистологически доказанный метастаз в отдаленном органе или метастаз в нере- } \\
\text { гионарных лимфоузлах размером более 0,2 мм }\end{array}$ \\
\hline
\end{tabular}

1 Категория смо не требует подтверждения с помощью методов визуализации.

\section{2. Клиническая (анатомическая) классификация}

\begin{tabular}{|c|c|c|c|}
\hline Категория Т & Категория N & Категория М & Стадия \\
\hline Tis & No & Mo & 0 \\
\hline T1 & No & M0 & IA \\
\hline TO & $\mathrm{N} 1 \mathrm{mi}$ & Mo & \multirow[t]{2}{*}{ IB } \\
\hline T1 & $\mathrm{N} 1 \mathrm{mi}$ & MO & \\
\hline TO & $\mathrm{N} 1$ & Mo & \multirow[t]{3}{*}{$\| \mathrm{A}$} \\
\hline T1 & N1 & Mo & \\
\hline $\mathrm{T} 2$ & No & MO & \\
\hline $\mathrm{T} 2$ & N1 & MO & \multirow[t]{2}{*}{ IIB } \\
\hline T3 & No & M0 & \\
\hline TO & N2 & Mo & \multirow[t]{5}{*}{ IIIA } \\
\hline T1 & N2 & M0 & \\
\hline $\mathrm{T} 2$ & N2 & MO & \\
\hline T3 & N1 & MO & \\
\hline T3 & N2 & M0 & \\
\hline $\mathrm{T} 4$ & No & M0 & \multirow[t]{3}{*}{ IIIB } \\
\hline T4 & N1 & Mo & \\
\hline T4 & N2 & Mo & \\
\hline Любая Т & N3 & M0 & IIIC \\
\hline Любая Т & Любая N & M1 & IV \\
\hline
\end{tabular}

\section{3. Гистологическая степень злокачественности опухоли (G)}

\begin{tabular}{|l|l|}
\hline Категория G & Критерии G \\
\hline Gx & Категория G не может быть определена \\
\hline G1 & Низкая степень злокачественности (благоприятный вариант), 3-5 баллов по шкале SBR ${ }^{1}$ \\
\hline G2 & Умеренная степень злокачественности (промежуточный вариант), 6-7 баллов по шкале SBR \\
\hline G3 & Высокая степень злокачественности (неблагоприятный вариант), 8-9 баллов по шкале SBR \\
\hline
\end{tabular}

1 SBR- - ккала Scarff-Bloom-Richardson, Ноттингемская модификация. 


\section{2. РАННИЙ (ПЕРВИЧНО ОПЕРАБЕЛЬНЫЙ)}

\section{И МЕСТНОРАСПРОСТРАНЕННЫЙ (ПЕРВИЧНО НЕ ОПЕРАБЕЛЬНЫЙ) РАК МОЛОЧНОЙ ЖЕЛЕЗЫ}

\section{1. Диагностика}

Диагноз РМЖ основывается на данных осмотра, результатах инструментальных методов обследования и патоморфологическом заключении. Первичное обследование должно быть проведено до всех видов лечебных воздействий и включает в себя:

- выяснение жалоб и сбор анамнеза с целью выявления клинико-анамнестических особенностей пациента и заболевания, а также факторов, которые могут повлиять на тактику дальнейшего обследования и лечения;

- общий осмотр, пальпацию, перкуссию и аускультацию внутренних органов, пальпацию молочных желез и зон регионарного метастазирования (подмышечных, над-, подключичных) с целью оценки общего состояния пациента и определения клинической стадии заболевания;

- общий (клинический) анализ крови развернутый;

- биохимический общетерапевтический анализ крови, включая показатели функции печени (билирубин, АЛТ, АСТ, ЩФ), почек (мочевина, креатинин), уровень глюкозы, кальция;

- исследование свертывающей системы крови (коагулограмма);

- общий (клинический) анализ мочи;

- билатеральную маммографию +УЗИ молочных желез и регионарныхзон; МРТ молочных желез - по показаниям ";

- R-графию органов грудной клетки; КТ/MPТ органов грудной клетки - по показаниям²;

- УзИ органов брюшной полости и малого таза; КТ / МРТ органов брюшной полости и малого таза с контрастированием - по показаниям²;

- радиоизотопное исследование скелета + рентгенографию и/или КТ / МРТ зон накопления РФП - по показаниям ${ }^{2}$;

- биопсию опухоли с патоморфологическим исследованием опухолевой ткани;

- определение в опухолевой ткани РЭ, РП, НЕR2 и Кі67;

- исследование уровня ФСГ и общего эстрадиола в сыворотке крови для оценки функции яичников ${ }^{3}$ (см. раздел 2.2.1.5, «Критерии менопаузы»);

1 Показаниями к выполнению МРТ молочных желез являются возраст до 30 лет, наличие герминальных мутаций BRCA1/2, высокая рентгенологическая плотность молочных желез, наличие имплантатов молочных желез при невозможности выполнения качественного маммографического исследования, наличие долькового рака in situ.

2 При местно-распространенном РМЖ (N+, размеры первичной опухоли $\geq 5 \mathrm{~cm})$, агрессивном фенотипе (тройной негативный, HER2 положительный), клинических или лабораторных признаках, подозрительных в отношении метастазов.

3 При гормонозависимом РМЖу пациенток моложе 60 лет с отсутствием менструаций. 
- консультацию медицинского генетика с определением герминальных мутаций BRCA1 / 2 методом ПЦР при следующих показаниях:

- отягощенный семейный анамнез (наличие у близких родственников РМЖ в возрасте $\leq 50$ лет, РМЖ у мужчины, рака яичников, метастатического рака предстательной железы, рака поджелудочной железы);

- пациенты моложе 45 лет;

- пациенты моложе 60 лет с тройным негативным фенотипом РМж;

- первично множественный РМЖ;

- РМЖ у мужчин.

Патоморфологический диагноз устанавливается с помощью биопсии первичной опухоли, которая должна быть выполнена до всех видов лечебных воздействий. Для адекватного клинического стадирования и определения оптимальной тактики лечения в дополнение к верификации опухоли в молочной железе рекомендуется морфологическое исследование подозрительных в отношении метастатического поражения регионарных лимфатических узлов (цитологическое или гистологическое и ИГХ). Биопсию опухоли рекомендуется выполнять, даже если на первом этапе планируется оперативное лечение. В отдельных (исключительных) случаях при невозможности выполнения биопсии опухоли рекомендуется выполнить тонкоигольную аспирационную биопсию (пункцию) опухоли (желательно под навигационным контролем) с цитологическим исследованием микропрепарата для морфологического подтверждения диагноза. При назначении неоадъювантной системной терапии полноценное клиническое стадирование должно быть проведено до начала лечения.

Определение в опухоли уровня экспрессии РЭ, РП, HER2 и Кі67 является обязательным; предпочтение отдается ИГХ методу. В отчет об исследовании рецепторного статуса необходимо включить не только данные о процентном содержании клеток, положительных по РЭ и РП, но и об интенсивности окрашивания. Опухоли с содержанием < $1 \%$ окрашенных на Рэ ядер считаются отрицательными по РЭ, с содержанием от 1 до $10 \%$ окрашенных ядер - слабоположительными, с содержанием > $10 \%$ окрашенных ядер - положительными по РЭ. Определение РП дополняет прогностическую характеристику опухоли и служит контролем возможного ложноотрицательного результата определения РЭ. Больные с опухолями, положительными по РП и отрицательными по Рэ могут быть кандидатами для Гт, однако, данные об эффективности этого метода в данной подгруппе больных ограничены.

Интерпретация морфологом результатов определения РЭ должна включать оценку конкордантности результатов ИГХ и гистологического исследований. Так, например, дольковые и протоковые инвазивные карциномы низкой степени злокачественности, «чистые» тубулярные, крибриформные и муцинозные карциномы, а также инкапсулированная и солидная папиллярные карциномы крайне редко бывают отрицательными по РЭ, в то время как метапластическая карцинома (все типы), аденокистозная карцинома (и другие карциномы, похожие на рак слюнной железы), секреторная карцинома и карцинома с апокринной 
дифференцировкой, наоборот, крайне редко бывают положительными по РЭ. При дискордантности данных гистологического и ИГХ исследований клиницист должен обсудить с морфологом возможные причины расхождения в полученных результатах и при необходимости назначить повторное тестирование или получение мнения второго морфолога с целью уточнения иммунофенотипа опухоли.

Определение HER2 должно проводиться только в инвазивном компоненте опухоли. При неопределенном результате ИГX анализа HER2 (2 +) следует провести определение амплификации гена HER2 методом in situ гибридизации (FISH, CISH или SISH).

Заключительные клинический и патоморфологический диагнозы устанавливаются в соответствии с действующими классификациями ВОЗ и TNM после изучения всех удаленных тканей. При патоморфологическом исследовании удаленной опухоли должны быть определены:

- гистологический вариант опухоли;

- степень злокачественности;

- состояние краев резекции;

- выраженность лимфоваскулярной инвазии;

- состояние подмышечных лимфоузлов;

- содержание РЭ, РП, HER2 и Кі67 ИГХ методом; в случае отрицательных значений РЭ, РП и HER2 по данным ИГХ исследования биопсийного материала рекомендуется повторное определение этих рецепторов в удаленной опухоли и/или метастатических лимфоузлах с учетом возможной гетерогенности опухоли;

- выраженность патоморфологического ответа в первичной опухоли и регионарных лимфоузлах (в случае предоперационной лекарственной терапии); предпочтительной для оценки степени выраженности патоморфологического ответа является система RCB (Residual Cancer Burden; бесплатный онлайн калькулятор доступен на сайте http://www.mdanderson.org/education-andresearch / resources-for-professionals / clinical-tools-and-resources / clinicalcalculators/calculators-cellularity-guide. pdf), однако, может использоваться и любой другой способ с указанием его варианта (по автору).

\section{2. Лечение}

Алгоритм лечебно-диагностических мероприятий при различных стадиях РМЖ представлен на рис. 1. 


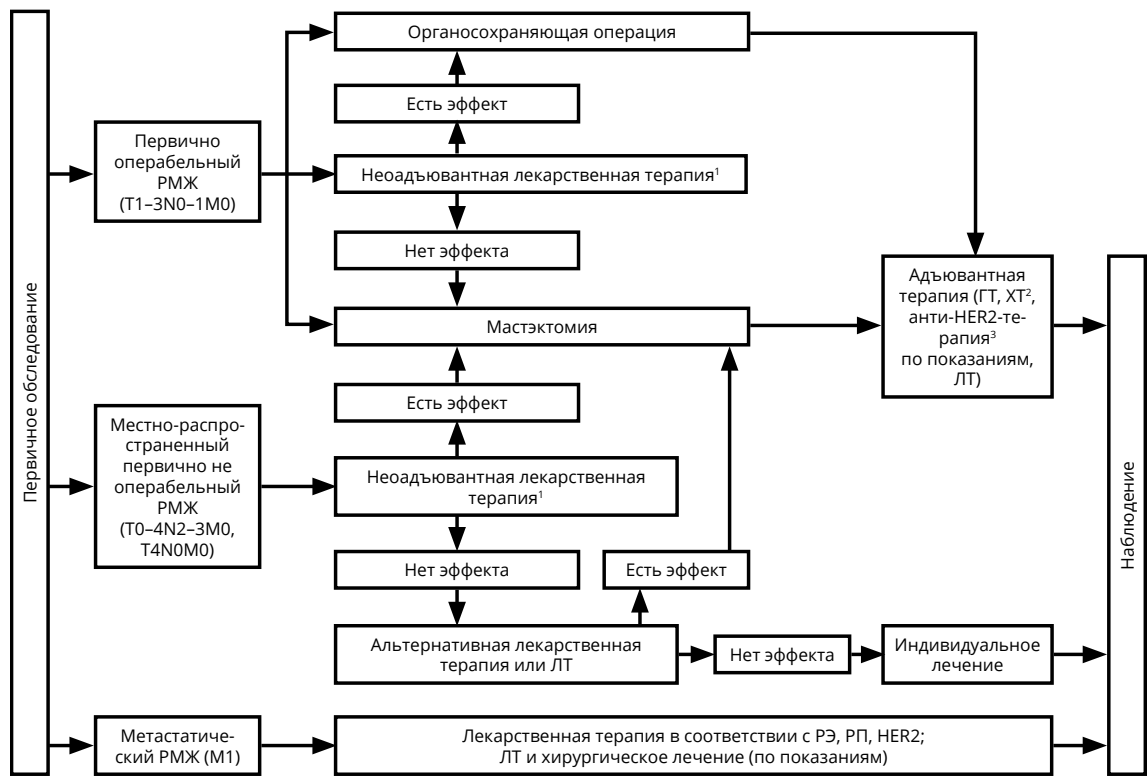

1 Неоадъювантная лекарственная терапия при I стадии рекомендуется только в рамках клинических исследований. Неоадъювантную ХТ рекомендуется проводить с использованием стандартных режимов (табл. 8) и обязательным соблюдением рекомендуемой дозовой интенсивности (стандартные дозы и интервалы между курсами). При отсутствии необходимых материальных ресурсов, гарантирующих проведение рекомендуемой неоадъювантной лекарственной терапии (антрациклины, таксаны, трастузумаб, пертузумаб, филграстим), при первично операбельном РМЖ рекомендуется на первом этапе выполнить хирургическое лечение.

2 Адъювантная ХТ не рекомендуется больным, получившим неоадъювантнуюХТ в полном объеме. В тех случаях, когда неоадъювантная ХТ по каким-либо причинам не была полностью проведена до операции, рекомендуется проведение недостающих циклов в послеоперационном периоде; больным РМЖ с тройным негативным фенотипом (отрицательные РЭ, РП и HER2), получившим неоадъювантную ХТ антрациклинами и таксанами в стандартном объеме, при наличии инвазивной резидуальной опухоли, соответствующей $R C B$ II-III или, при невозможности оценки по RCB, при резидуальной опухоли в регионарных лимфатических узлах (независимо от степени патоморфоза в первичной опухоли в молочной железе) или при резидуальной опухоли в молочной железе, соответствующей 0-І/ степени лекарственного патоморофоза по Лавниковой (независимо от состояния регионарных лимфатических узлов), рекомендуется адъювантная ХТ капецитабином (2000-2500 мг/м² в 1-й-14-й дни каждые 3 нед. в течение 6 мес.) (табл. 4).

3 Больным HER2-положительным РМЖ, получившим неоадъювантную лекарственную терапию антрациклинами и/или таксанами в сочетании с трастузумабом ( пертузумаб), при наличии инвазивной резидуальной опухоли, соответствующей RCB II-III или, при невозможности оченки по RCB, при резидуальной опухоли в регионарных лимфатических узлах (независимо от степени патоморфоза в первичной опухоли в молочной железе) или при резидуальной опухоли в молочной железе, соответствующей 0-II степени лекарственного патоморофоза по Лавниковой (независимо от состояния регионарных лимфатических узлов), рекомендуется адъювантная терапия трастузумабом-эмтанзином 3,6 мг/кг в/в в 1-й день 1 раз в 3 нед., 14 циклов (табл. 5).

Рисунок 1. Алгоритм лечебно-диагностических мероприятий в зависимости от стадии рака молочной железы. 


\subsection{1. Ранний (первично операбельный) рак молочной железы (0, I, IIA, IIB, IIIA стадии)}

\subsubsection{1. Стадия 0 (TisNOMO), протоковый рак in situ}

Для профилактики развития вторых опухолей в контралатеральной и резецированной (в случае выполнения органосохраняющей операции) молочной железе при положительных РЭ во внутрипротоковом (in situ) раке рекомендуется рассмотреть назначение адъювантной гормонотерапии с использованием одного из следующих режимов:

- тамоксифен 20 мг/сут. внутрь ежедневно в течение 5 лет у больных в преи постменопаузе

- тамоксифен 5 мг/сут. внутрь ежедневно в течение 3 лет у больных в преи постменопаузе;

- ингибиторы ароматазы (летрозол 2,5 мг/сут. или анастрозол 1 мг/сут. или эксеместан 25 мг/сут. внутрь ежедневно) в течение 5 лет у больных в стойкой менопаузе.

Овариальная супрессия при TisNOMO не показана. Химиотерапия при TisNOMO не показана.

\subsubsection{2. Общие принципы адъювантной лекарственной терапии инвазивного РМЖ}

Адъювантная лекарственная терапия проводится в дополнение к локальным (хирургическому и лучевому) методам лечения и позволяет снизить риск рецидива болезни и смерти. При планировании адъювантной лекарственной терапии необходимо оценить прогноз, ожидаемую пользу адъювантного лечения, возможные побочные эффекты и сопутствующую патологию, а также учесть предпочтения больной. Возраст сам по себе не является ограничением для лекарственной терапии при отсутствии сопутствующей патологии.

При опухолях небольших размеров (<0,5см) в сочетании с N0, являющихся прогностически благоприятными, адъювантная лекарственная терапия обладает минимальной эффективностью. Назначение адъювантной ГТ (при гормонозависимых опухолях) в такой ситуации имеет целью профилактику вторых (контралатеральных) гормонозависимых опухолей.

План адъювантной лекарственной терапии основывается на принадлежности опухоли к одному из молекулярно-биологических подтипов и стадии заболевания (табл. 2, 3). Адъювантная лекарственная терапия должна начинаться с XT, если таковая показана. Не рекомендуется одновременное введение антрациклинов и анти-HER2 препаратов ввиду высокого риска кардиотоксичности; адъювантная XТ таксан-содержащими режимами должна проводиться одновременно с анти-HER2-терапией, если таковая показана. ГТ, если таковая показана, должна начинаться после завершения XT и проводиться одновременно с продолжающейся анти-HER2-терапией (у больных с положительным HER2 статусом опухоли). Лт, если таковая показана, должна начинаться после 
завершения ХT и проводиться одновременно с ГТ и анти-HER2-терапией. Рекомендуемая последовательность различных методов адъювантной терапии представлена на рис. 2.

Адъювантная XT, как правило, не рекомендуется больным, получившим стандартный объем неоадъювантной ХТ (табл. 8); исключение составляют больные тройным негативным и HER2-позитивным РМЖ с выраженной резидуальной опухолью (RCB II-III) (табл. 4, 5). В тех случаях, когда план неоадъювантной XT по каким-либо причинам не был полностью выполнен, рекомендуется проведение недостающих курсов лечения в послеоперационном периоде.

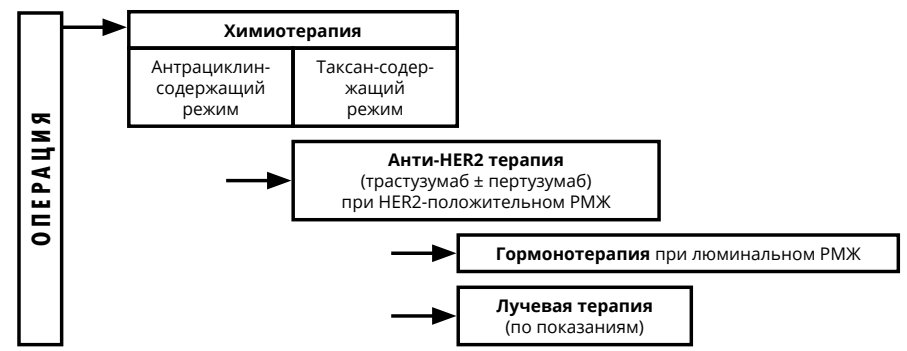

Рисунок 2. Рекомендуемая последовательность различных методов адъювантной терапии рака молочной железы.

Таблица 2. Суррогатное определение молекулярно-биологических подтипов рака молочной железы

\begin{tabular}{|c|c|}
\hline Молекулярно-биологический подтип & Клинико-патологическое (суррогатное) определение подтипа \\
\hline Люминальный A & $\begin{array}{l}\text { Наличие всех факторов: } \\
\text { - } \text { РЭ положительные } \\
\text { - } \text { НЕR2 отрицательный } \\
\text { - } \text { Кі67 низкий }(\leq 20 \%) \\
\text { - } \\
\text { РП высокие }(\geq 20 \%)\end{array}$ \\
\hline Люминальный В (HER2 отрицательный) & $\begin{array}{l}\text { - РЭ положительные } \\
\text { - } \text { НЕR2 отрицательный и наличие одного из следующих } \\
\text { факторов: } \\
\text { - Кі67 высокий }(\geq 30 \%) \\
\text { - } \text { РП низкие }(<20 \%)\end{array}$ \\
\hline Люминальный В (HER2 положительный) & $\begin{array}{l}\text { · } \text { РЭ положительные } \\
\text { - } \text { НЕR2 положительный } \\
\text { · } \text { Кі67 любой } \\
\text { · } \text { РП любые }\end{array}$ \\
\hline HER2 положительный (не люминальный) & $\begin{array}{l}\text { · HER2 положительный } \\
\text { · } \text { РЭ и РП отрицательные } \\
\text { · Кі67 любой }\end{array}$ \\
\hline Базальноподобный & $\begin{array}{l}\text { - отрицательные РЭ, РП, НЕR2 (тройной негативный } \\
\text { протоковый) }\end{array}$ \\
\hline
\end{tabular}


1 Значение Кі67 следует оценивать, исходя из опыта локальной патоморфологической лаборатории: например, если медиана значений Кі67 при гормонозависимом РМЖ составляет в данной лаборатории 20\%, то значение этого показателя, равное $\leq 10 \%$, следует расценивать как низкое, $a \geq 30 \%$ - как высокое; при уровне Кі67 от 20 до $30 \%$ при решении вопроса о тактике лечения следует учитывать другие, клинико-морфологические факторы прогноза (стадию, степень злокачественности, морфологический вариант и др.).

2 Пороговым значением при определении РП считается $20 \%$.

Таблица 3. Рекомендуемый алгоритм назначения адъювантной системной терапии в зависимости от молекулярно-биологического подтипа и степени распространенности рака молочной железы

\begin{tabular}{|c|c|c|}
\hline $\begin{array}{l}\text { Молекулярно- } \\
\text { биологический } \\
\text { подтип }\end{array}$ & $\begin{array}{l}\text { Рекомендуемая } \\
\text { адъювантная } \\
\text { системная терапия }\end{array}$ & Примечания \\
\hline Люминальный А & $\begin{array}{l}\text { Только ГТ } \\
\text { в большинстве } \\
\text { случаев }\end{array}$ & $\begin{array}{l}\text { Назначение адъювантной ХT (в дополнение к адъювантной ГT) } \\
\text { должно быть рассмотрено при наличии одного из следующих } \\
\text { факторов: } \\
\text { • большая степень распространения болезни: } \\
\text { - } \geq 4 \text { пораженных метастазами регионарных лимфатических } \\
\text { узлов; } \\
\text { - } \geq \text { ТЗ. } \\
\text { В качестве ХT рекомендуются режимы АС/ЕС (4 цикла) или DC } \\
\text { (доцетаксел + циклофосфамид) (4 цикла) (табл. 4, рис. 2) }\end{array}$ \\
\hline $\begin{array}{l}\text { Люминальный В } \\
\text { (НЕR2 отрица- } \\
\text { тельный) }\end{array}$ & $\begin{array}{l}\text { ХТ в большинстве } \\
\text { случаев + ГТ }\end{array}$ & 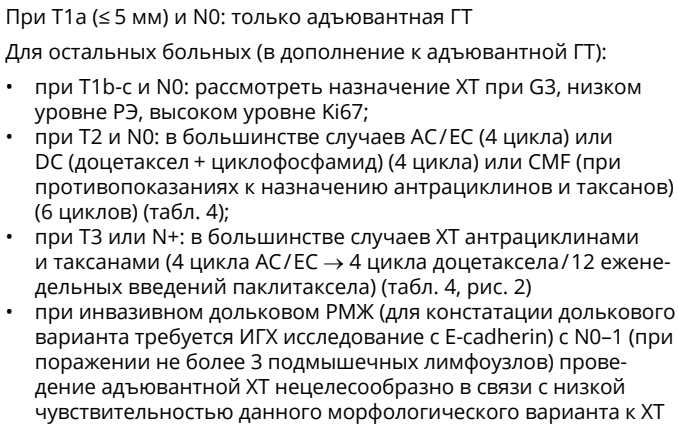 \\
\hline $\begin{array}{l}\text { Люминальный } \\
\text { В (HER2 положи- } \\
\text { тельный) }\end{array}$ & $\begin{array}{l}\text { XT + анти-HER2- } \\
\text { терапия + ГТ }\end{array}$ & 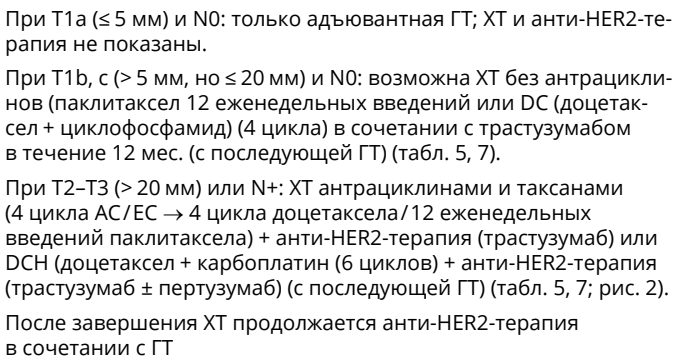 \\
\hline
\end{tabular}




\begin{tabular}{|c|c|c|}
\hline $\begin{array}{l}\text { Молекулярно- } \\
\text { биологический } \\
\text { подтип }\end{array}$ & $\begin{array}{l}\text { Рекомендуемая } \\
\text { адъювантная } \\
\text { системная терапия }\end{array}$ & Примечания \\
\hline $\begin{array}{l}\text { HER2 положи- } \\
\text { тельный (не } \\
\text { люминальный) }\end{array}$ & $\begin{array}{l}\text { XT + анти-HER2- } \\
\text { терапия }\end{array}$ & 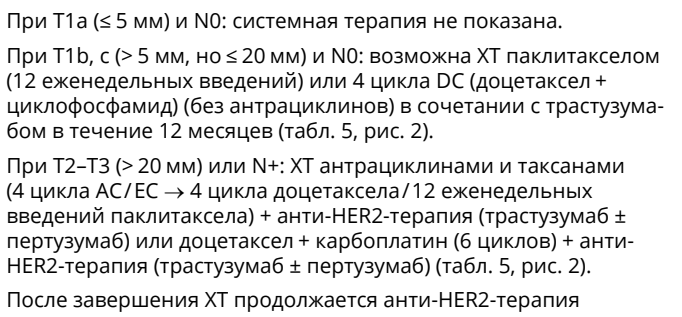 \\
\hline $\begin{array}{l}\text { Тройной } \\
\text { негативный }\end{array}$ & $\begin{array}{l}\text { ХТ с включением } \\
\text { антрациклинов } \\
\text { и таксанов }\end{array}$ & 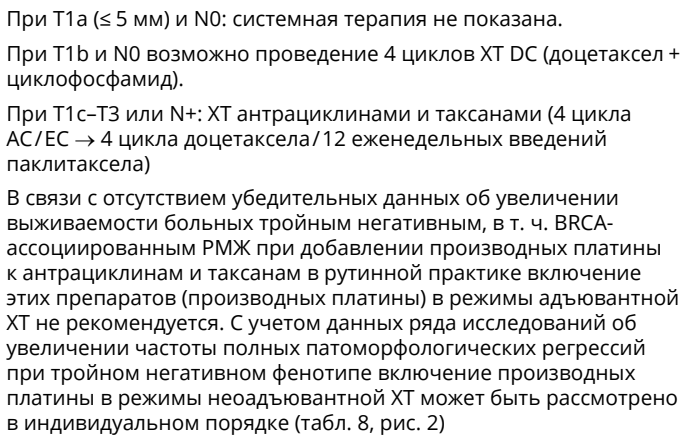 \\
\hline
\end{tabular}

\subsubsection{3. Адъювантная химиотерапия HER2-отрицательного рака молочной железы}

Следует использовать стандартные режимы с соблюдением рекомендуемой дозовой интенсивности; необходимо избегать необоснованной (в отсутствие токсичности) редукции доз препаратов и увеличения интервалов между курсами. Рекомендуется последовательное (а не одновременное!) использование антрациклинов и таксанов; при назначении паклитаксела предпочтительно еженедельное введение, особенно при тройном негативном варианте. Рекомендуемые режимы адъювантной XT HER2-отрицательного РМЖ представлены в табл. 4.

Tаблица 4. Рекомендуемые режимы адъювантной химиотерапии HER2-отрицательного рака молочной железы

\begin{tabular}{|c|c|}
\hline$A C \times 4^{1}$ & $\begin{array}{l}\text { Доксорубицин } 60 \text { мг/м² в/в в 1-й день + циклофосфамид } 600 \text { мг/м² в/в в 1-й день } \\
1 \text { раз в } 3 \text { нед., } 4 \text { цикла }\end{array}$ \\
\hline$A C \times 4^{1,2,3}$ & $\begin{array}{l}\text { Доксорубицин } 60 \text { мг/м² в/в в 1-й день + циклофосфамид } 600 \text { мг/м² в/в в 1-й день } \\
1 \text { раз в } 2 \text { нед., } 4 \text { цикла }\end{array}$ \\
\hline$A C \times 4 \rightarrow D \times 4^{1}$ & $\begin{array}{l}\text { АС (доксорубицин } 60 \text { мг/м² в/в в 1-й день + циклофосфамид } 600 \text { мг/м² в/в в 1-й день) } \\
1 \text { раз в } 3 \text { нед., } 4 \text { цикла } \rightarrow \text { доцетаксел } 75 \text { мг/м² в/в в 1-й день } 1 \text { раз в } 3 \text { нед., } 4 \text { цикла }\end{array}$ \\
\hline
\end{tabular}




\begin{tabular}{|c|c|}
\hline $\mathrm{AC} \times 4 \rightarrow \mathrm{P} \times 12^{1,4}$ & $\begin{array}{l}\text { АС (доксорубицин } 60 \text { мг/м² в/в в 1-й день + циклофосфамид } 600 \text { мг/м² в/в в 1-й день) } \\
1 \text { раз в } 3 \text { нед., } 4 \text { цикла } \rightarrow \text { паклитаксел } 80 \text { мг/м² в/в еженедельно, } 12 \text { введений }\end{array}$ \\
\hline $\mathrm{AC} \times 4 \rightarrow \mathrm{P} \times 4^{1,5}$ & $\begin{array}{l}\text { АС (доксорубицин } 60 \text { мг/м² в/в в 1-й день + циклофосфамид } 600 \text { мг/м² в/в в 1-й день) } \\
1 \text { раз в } 3 \text { нед., } 4 \text { цикла } \rightarrow \text { паклитаксел } 175 \text { мг/м² в/в в 1-й день } 1 \text { раз в } 3 \text { нед., } 4 \text { цикла }\end{array}$ \\
\hline $\mathrm{AC} \times 4 \rightarrow \mathrm{P} \times 4^{1,2,3}$ & $\begin{array}{l}\text { АС (доксорубицин } 60 \text { мг/м² в/в в 1-й день + циклофосфамид } 600 \text { мг/м² в/в в 1-й день) } \\
1 \text { раз в } 2 \text { нед., } 4 \text { цикла } \rightarrow \text { паклитаксел } 175 \text { мг/м² в/в в 1-й день } 1 \text { раз в } 2 \text { нед., } 4 \text { цикла }\end{array}$ \\
\hline $\mathrm{AC} \times 4 \rightarrow \mathrm{P} \times 12^{1,2,3,4}$ & $\begin{array}{l}\text { АС (доксорубицин } 60 \text { мг/м² в/в в 1-й день + циклофосфамид } 600 \text { мг/м² в/в в 1-й день) } \\
1 \text { раз в } 2 \text { нед., } 4 \text { цикла } \rightarrow \text { паклитаксел } 80 \text { мг/м² в/в еженедельно, } 12 \text { введений }\end{array}$ \\
\hline $\mathrm{DC} \times 4^{3}$ & $\begin{array}{l}\text { Доцетаксел } 75 \text { мг/м² в/в в 1-й день + циклофосфамид } 600 \text { мг/м² в/в в 1-й день } 1 \text { раз } \\
\text { в } 3 \text { нед., } 4 \text { цикла }\end{array}$ \\
\hline $\mathrm{CMF}^{6}$ & $\begin{array}{l}\text { Циклофосфамид } 100 \text { мг/м² внутрь в 1-й-14-й дни + метотрексат } \\
40 \text { мг/м² в/в в 1-й и 8-й дни + фторурацил } 600 \text { мг/м² в/ в в 1-й и 8-й дни каждые } 4 \text { нед. } \\
6 \text { циклов }\end{array}$ \\
\hline $\begin{array}{l}\text { Капецитабин } \\
\text { (монотерапия) }\end{array}$ & Капецитабин 2000-2500 мг/м² внутрь в 1-й-14-й дни каждые 3 нед. в течение 6 мес. \\
\hline
\end{tabular}

1 Доксорубицин может быть заменен на эпирубицин в курсовой дозе 90-100 мг/м² (режим ЕС).

2 Режим с уплотненным введением химиопрепаратов следует рассмотреть при быстро пролиферирующих (с высоким Кі67) вариантах РМЖ.

3 Требуется профилактическое назначение Г-КСФ (филграстим 5 мкг/кг n/к через 24-72 часа после окончания введения химиопрепаратов и до восстановления нормального числа нейтрофилов после надира или пэгфилграстим 6 мг или эмпэгфилграстим 7,5 мг n/к, не менее чем через 24 часа после окончания и не ранее чем за 14 дней до введения химиопрепаратов).

4 При использовании еженедельных введений паклитаксела объем стандартной премедикации может быть сокращен (на усмотрение лечащего врача) и проводиться по схеме: 1-2-й курсы - дексаметазон 10 мг в/м или внутрь за 12 и 6 часов до введения паклитаксела, блокаторы рецепторов Н1 (дифенгидрамин 50 мг или эквивалентные дозы аналогов) в/в струйно за 30-60 мин. до введения паклитаксела, блокаторы рецепторов Н2 (фамотидин 50 мг или эквивалентные дозы аналогов) в/в струйно за 30-60 мин. до введения паклитаксела. При отсутствии реакций гиперчувствительности на первых двух курсах в дальнейшем возможно введение дексаметазона 8 мг в/в за 30-60 мин. до введения паклитаксела, а введение блокаторов Н1/H2 гистаминовых рецепторов - только в случае предшествовавших реакций гиперчувствительности. Введение паклитаксела может проводиться при АЧН $\geq 1,0 \times 10^{9} / л$ и количестве тромбочитов $\geq 100,0 \times 10^{9} / л$.

5 Режим введения паклитаксела 175 мг/м² 1 раз в 3 недели является менее эффективным по сравнению с еженедельным, особенно при тройном негативном подтипе РМЖ.

6 При противопоказаниях к назначению антрациклинов и таксанов.

7 Рекомендуется больным РМЖ с тройным негативным фенотипом (отрицательные РЭ, РП и HER2), получившим неоадъювантную ХТ антрациклинами и таксанами в стандартном объеме, при наличии инвазивной резидуальной опухоли, соответствующей RCB II-III или, при невозможности оценки по RCB, при резидуальной опухоли в регионарных лимфатических узлах (независимо от степени патоморфоза в первичной опухоли в молочной железе) или при резидуальной опухоли в молочной железе, соответствующей 0-/l степени лекарственного патоморофоза по Лавниковой (независимо от состояния регионарных лимфатических узлов).

\subsubsection{4. Адъювантная терапия HER2-положительного рака молочной железы}

Адъювантная терапия HER2-положительного РМЖ включает XT, антиHER2-терапию и ГТ (при наличии в опухоли РЭ и РП). Рекомендуемые режимы адъювантной лекарственной терапии HER2-положительного РМж представлены в табл. 5. 
Таблица 5. Рекомендуемые режимы адъювантной лекарственной терапии HER2-положительного рака молочной железы

\begin{tabular}{|c|c|}
\hline $\begin{array}{l}\text { AC } \times 4 \rightarrow \\
(D+\text { трастузумаб) } \times 41,2,3,4\end{array}$ & $\begin{array}{l}\text { АС (доксорубицин } 60 \text { мг/м² в/в в 1-й день + циклофосфамид } \\
600 \text { мг/м² в/в в 1-й день) } 1 \text { раз в } 3 \text { нед., } 4 \text { цикла } \rightarrow \text { доцетаксел } \\
75 \text { мг/м² в/в в 1-й день } 1 \text { раз в } 3 \text { нед., } 4 \text { цикла + трастузумаб } 6 \text { мг/кг (на- } \\
\text { грузочная доза } 8 \text { мг/кг) в/в в 1-й день } 1 \text { раз в } 3 \text { нед.; далее - трастузумаб } \\
6 \text { мг/кг в/в } 1 \text { раз в } 3 \text { нед. до общей длительности } 12 \text { мес. }\end{array}$ \\
\hline $\begin{array}{l}\text { АC } \times 4 \rightarrow \\
(P+\text { трастузумаб }) \times 12^{1,2,3,4,10}\end{array}$ & $\begin{array}{l}\text { АС (доксорубицин } 60 \text { мг/м² в/в в 1-й день + циклофосфамид } \\
600 \text { мг/м² в/в в 1-й день) } 1 \text { раз в } 3 \text { нед., } 4 \text { цикла } \rightarrow \text { паклитаксел } \\
80 \text { мг/м² в/в еженедельно, } 12 \text { введений + трастузумаб } 2 \text { мг/кг (нагрузоч- } \\
\text { ная доза } 4 \text { мг/кг) в/в еженедельно } 12 \text { введений, далее - трастузумаб } \\
6 \text { мг/кг в/в } 1 \text { раз в } 3 \text { нед. до общей длительности } 12 \text { мес. }\end{array}$ \\
\hline$\left(\mathrm{P}+\right.$ трастузумаб) $\times 12^{5,10}$ & $\begin{array}{l}\text { Паклитаксел } 80 \text { мг/м² в/в еженедельно, } 12 \text { введений + трастузумаб } 2 \text { мг/кг } \\
\text { (нагрузочная доза } 4 \text { мг/кг) в/в еженедельно } 12 \text { введений; далее - трасту- } \\
\text { зумаб } 6 \text { мг/кг в/в } 1 \text { раз в } 3 \text { нед. до общей длительности } 12 \text { мес. }\end{array}$ \\
\hline$\left(D C+\right.$ трастузумаб) $\times 4^{5,6}$ & $\begin{array}{l}\text { Доцетаксел } 75 \text { мг/м² в/в в 1-й день + циклофосфамид } \\
600 \text { мг/м² в/в в 1-й день } 1 \text { раз в } 3 \text { нед. + трастузумаб } 6 \text { мг/кг (нагрузочная } \\
\text { доза } 8 \text { мг/кг) в/в в 1-й день } 1 \text { раз в } 3 \text { нед., } 4 \text { цикла; далее - трастузумаб до } \\
\text { общей длительности } 12 \text { мес. }\end{array}$ \\
\hline $\mathrm{DCH} \times 6^{2,3,4}$ & $\begin{array}{l}\text { Доцетаксел } 75 \text { мг/м² в/в в 1-й день } 1 \text { раз в } 3 \text { нед. + карбоплатин } \\
\text { AUC- } 6 \text { в/в в 1-й день } 1 \text { раз в } 3 \text { нед. + трастузумаб } 6 \text { мг/кг (нагрузочная } \\
\text { доза } 8 \text { мг/кг) в/в в 1-й день } 1 \text { раз в } 3 \text { нед., } 6 \text { циклов; далее - трастузумаб } \\
6 \text { мг/кг в/в } 1 \text { раз в } 3 \text { нед. до общей длительности } 12 \text { мес. }\end{array}$ \\
\hline $\begin{array}{l}\text { АC } \times 4 \rightarrow \\
\left(\mathrm{P}+\text { трастузумаб) } \times 12^{1,2,3,4,6,7,10}\right.\end{array}$ & $\begin{array}{l}\text { АС (доксорубицин } 60 \text { мг/м² в/в в 1-й день + циклофосфамид } \\
600 \text { мг/м² в/в в 1-й день) } 1 \text { раз в } 2 \text { нед., } 4 \text { курса } \rightarrow \text { паклитаксел } \\
80 \text { мг/м² в/в еженедельно, } 12 \text { введений + трастузумаб } 2 \text { мг/кг (нагрузоч- } \\
\text { ная доза } 4 \text { мг/кг) в/в еженедельно } 12 \text { введений, далее - трастузумаб } \\
6 \text { мг/кг в/в } 1 \text { раз в } 3 \text { нед. до общей длительности } 12 \text { мес. }\end{array}$ \\
\hline $\begin{array}{l}\text { АC } \times 4 \rightarrow \\
(P+\text { трастузумаб }) \times 41,2,3,4,6,7\end{array}$ & $\begin{array}{l}\text { АС (доксорубицин } 60 \text { мг/м² в/в в 1-й день + циклофосфамид } \\
600 \text { мг/м²в/в в 1-й день) } 1 \text { раз в } 2 \text { нед., } 4 \text { цикла } \rightarrow \text { паклитаксел } \\
175 \text { мг/м² в/в в 1-й день } 1 \text { раз в } 2 \text { нед., } 4 \text { цикла + трастузумаб } 2 \text { мг/кг } \\
\text { (нагрузочная доза } 4 \text { мг/кг) в/в еженедельно; далее - трастузумаб } 6 \text { мг/кг } \\
\text { в/в } 1 \text { раз в } 3 \text { нед. до общей длительности } 12 \text { мес. }\end{array}$ \\
\hline $\begin{array}{l}\text { АС } \times 4 \rightarrow(\text { таксаны }+ \\
\text { трастузумаб + } \\
\text { пертузумаб) } \times 4^{1,2,3,8}\end{array}$ & $\begin{array}{l}\text { АС (доксорубицин } 60 \text { мг/м² в/в в 1-й день + циклофосфамид } \\
600 \text { мг/м² в/в в 1-й день) } 1 \text { раз в } 3 \text { нед., } 4 \text { цикла } \rightarrow \text { таксаны (доцетак- } \\
\text { сел } 75 \text { мг/м² в/в в 1-й день каждые } 3 \text { нед. } 4 \text { цикла или паклитаксел } \\
80 \text { мг/м² в/в еженедельно } 12 \text { введений) + трастузумаб } 6 \text { мг/кг (нагрузоч- } \\
\text { ная доза } 8 \text { мг/кг) в/в в 1-й день } 1 \text { раз в } 3 \text { нед. + пертузумаб } 420 \text { мг (на- } \\
\text { грузочная доза } 840 \text { мг) в/в в 1-й день } 1 \text { раз в } 3 \text { нед.; общая длительность } \\
\text { введения трастузумаба и пертузумаба составляет } 12 \text { мес. }\end{array}$ \\
\hline$(\mathrm{DCH}+$ пертузумаб) × 62,3,8 & $\begin{array}{l}\text { Доцетаксел } 75 \text { мг/м² в/в в 1-й день } 1 \text { раз в } 3 \text { нед. + карбоплатин } \\
\text { AUC-6 в/в в 1-й день } 1 \text { раз в } 3 \text { нед. + трастузумаб } 6 \text { мг/кг (нагрузочная доза } \\
8 \text { мг/кг) в/в в 1-й день } 1 \text { раз в } 3 \text { нед. + пертузумаб } 420 \text { мг (нагрузочная } \\
\text { доза } 840 \text { мг) в/в в 1-й день } 1 \text { раз в } 3 \text { нед., } 6 \text { циклов; общая длительность } \\
\text { введения трастузумаба и пертузумаба составляет } 12 \text { мес. }\end{array}$ \\
\hline Трастузумаб-эмтанзин × $14^{9}$ & Трастузумаб-эмтанзин 3,6 мг/кг в/в в 1-й день 1 раз в 3 нед., до 14 циклов \\
\hline
\end{tabular}

1 Доксорубицин может быть заменен на эпирубицин в курсовой дозе 90-100 мг/м² (режим ЕС); не рекомендуется одновременное введение антрациклинов (доксорубицина и эпирубицина) и анти-HER2 препаратов (трастузумаба, пертузумаба) ввиду высокого риска кардиотоксичности; до и в процессе терапии антрациклинами и/или трастузумабом необходим контроль ФВлж с помощью ЭхоКГ с частотой 1 раз в 3 мес. (или чаще при наличии показаний).

2 Введение анти-HER2 препаратов (трастузумаба, пертузумаба) рекомендуется начинать одновременно с безантрациклиновым таксан-содержащим режимом. 
3 Возможно использование лекарственной формы трастузумаба для подкожного введения в дозе 600 мг/5 мл (независимо от массы тела пациента) 1 раз в 3 нед.; нагрузочная доза не требуется.

4 Оптимальная длительность адъювантной терапии трастузумабом составляет 12 мес., включая дооперационный этап в случае проведения неоадъювантной терапии.

5 Рекомендуется рассмотреть применение данного режима при T1b, c (>5 мм, но $\leq 20$ мм) и No.

6 Рекомендуется профилактическое назначение Г-КСФ (филграстим 5 мкг/кг n/к через 24-72 часа после окончания введения химиопрепаратов и до восстановления нормального числа нейтрофилов после надира или пэгфилграстим 6 мг или эмпэгфилграстим 7,5 мг n/к, не менее чем через 24 часа после окончания и не ранее чем за 14 дней до введения химиопрепаратов).

7 Режим суплотненным введением химиопрепаратов рекомендуется рассмотреть при быстро пролиферирующих (с высоким Кі67) вариантах РМЖ.

8 Режим рекомендуется больным с N2-3, не получавшим неоадъювантной лекарственной терапии; пертузумаб вводится в сочетании с трастузумабом в течение 12 мес.

9 Рекомендуется больным, получившим неоадювантную ХТ антрациклинами и/или таксанами и трастузумабом (士 пертузумабом) в стандартном объеме, при наличии инвазивной резидуальной опухоли, соответствующей RCB II-III или, при невозможности оченки по RCB, при резидуальной опухоли в регионарных лимфатических узлах (независимо от степени патоморфоза в первичной опухоли в молочной железе) или при резидуальной опухоли в молочной железе, соответствующей 0-II степени лекарственного патоморофоза по Лавниковой (независимо от состояния регионарных лимфатических узлов). В исследовании KATHERINE адъювантная ГТ и адьювантная Лт проводились одновременно с введением трастузумаба-эмтанзина. При досрочном прекращении введения трастузумаба-эмтанзина в связи с токсичностью следует продолжить введение трастузумаба до общей продолжительности анти-HER2 терапии 1 год, включая дооперационный этап.

10 При использовании еженедельных введений паклитаксела объем стандартной премедикации может быть сокращен (на усмотрение лечащего врача) и проводиться по схеме: 1-2-й курсы - дексаметазон 10 мг в/м или внутрь за 12 и 6 часов до введения паклитаксела, блокаторы рецепторов Н1 (дифенгидрамин 50 мг или эквивалентные дозы аналогов) в/в струйно за 30-60 мин. до введения паклитаксела, блокаторы рецепторов Н2 (фамотидин 50 мг или эквивалентные дозы аналогов) в/в струйно за 30-60 мин. до введения паклитаксела. При отсутствии реакций гиперчувствительности на первых двух курсах в дальнейшем возможно введение дексаметазона 8 мг в/в за 30-60 мин. до введения паклитаксела, а введение блокаторов H1/H2 гистаминовых рецепторов - только в случае предшествовавших реакций гиперчувствительности. Введение паклитаксела может проводиться при АЧН $\geq 1,0 \times 10^{9} / л$ и количестве тромбочитов $\geq 100,0 \times 10^{9} / л$.

\subsubsection{5. Адъювантная гормонотерапия рака молочной железы}

Адъювантная ГТ показана всем больным гормонозависимым РМЖ независимо от возраста, функции яичников, стадии заболевания, HER2 статуса, проведения нео- / адъювантной ХT или анти-HER2-терапии. Гормонозависимыми считаются опухоли с определяемой экспрессией Рэ в $\geq 1$ \% клеток инвазивного РМж. Выбор режима ГТ зависит от функции яичников (табл. 6, 7). 
таблица 6. Лекарственные препараты, рекомендуемые для адъювантной гормонотерапии рака молочной железы

\begin{tabular}{|l|l|}
\hline Антиэстрогены $^{1}$ & Тамоксифен 20 мг/сут. внутрь ежедневно \\
\hline Ингибиторы ароматазы & 2,3 \\
& Летрозол 2,5 мг/сут. внутрь ежедневно \\
& Анастрозол 1 мг/сут. внутрь ежедневно \\
& Эксеместан 25 мг/сут. внутрь ежедневно \\
\hline Аналоги ГРГ 4 & Гозерелин 3,6 мг п/к 1 раз в 28 дней \\
& Трипторелин 3,75 мг в/м 1 раз в 28 дней \\
& Бусерелин 3,75 мг в/м 1 раз в 28 дней \\
& Лейпрорелин 3,75 мг в/м 1 раз в 28 дней \\
\hline
\end{tabular}

1 Могут использоваться независимо от функции яичников; овариальная супрессия в дополнение к антиэстрогенам рекомендуется больным с сохранной функцией яичников при наличии факторов высокого риска рецидива (см. табл. 7); определение мутаций гена СУР2D6 для решения вопроса о назначении тамоксифена в рутинной практике не рекомендуется; следует избегать совместного назначения тамоксифена и ингибиторов CYP2D6.

2 Рекомендуется использовать только у больных в постменопаузе, противопоказаны больным с сохранной функцией яичников; у больных с сохранной функцией яичников для назначения ингибиторов ароматазы требуется овариальная супрессия.

3 Дольковый рак более чувствителен к ингибиторам ароматазы.

4 Рекомендуется использовать только у больных с сохранной функцией яичников при необходимости овариальной супрессии; назначаются в сочетании с антиэстрогенами или ингибиторами ароматазы; ГРГ рекомендуется вводить 1 раз в 28 дней.

таблица 7. Рекомендуемые режимы адъювантной гормонотерапии рака молочной железы в зависимости от функции яичников

\begin{tabular}{|c|c|}
\hline Режимы гормонотерапии & Примечания \\
\hline \multicolumn{2}{|l|}{ Пременопауза } \\
\hline \multicolumn{2}{|l|}{ Тамоксифен 5 лет } \\
\hline $\begin{array}{l}\text { Тамоксифен 2-3 года } \rightarrow \text { ингибиторы } \\
\text { ароматазы 2-3 года (суммарно - } 5 \text { лет) }\end{array}$ & $\begin{array}{l}\text { Для больных, достигших стойкой менопаузы к моменту } \\
\text { окончания приема тамоксифена }\end{array}$ \\
\hline Тамоксифен 10 лет & $\begin{array}{l}\text { При наличии по крайней мере одного фактора неблагоприят- } \\
\text { ного прогноза }\end{array}$ \\
\hline $\begin{array}{l}\text { Тамоксифен } 5 \text { лет } \rightarrow \text { ингибиторы } \\
\text { ароматазы } 2 \text { года }\end{array}$ & $\begin{array}{l}\text { Для больных, достигших стойкой менопаузы к моменту } \\
\text { окончания приема тамоксифена, при наличии по крайней } \\
\text { мере одного фактора неблагоприятного прогноза1 }\end{array}$ \\
\hline $\begin{array}{l}\text { Овариальная супрессия + тамоксифен или } \\
\text { ингибиторы ароматазы } 5 \text { лет }\end{array}$ & $\begin{array}{l}\text { При наличии по крайней мере одного фактора неблагоприят- } \\
\text { ного прогноза } 1,2,3,4\end{array}$ \\
\hline \multicolumn{2}{|l|}{ Постменопауза } \\
\hline \multicolumn{2}{|l|}{ Тамоксифен 5 лет } \\
\hline \multicolumn{2}{|l|}{ Ингибиторы ароматазы 5 лет } \\
\hline $\begin{array}{l}\text { Ингибиторы ароматазы 2-3 года, далее - } \\
\text { тамоксифен 2-3 года }\end{array}$ & $\begin{array}{l}\text { При использовании режимов переключения предпочтитель- } \\
\text { но на первом этапе использовать ингибиторы ароматазы }\end{array}$ \\
\hline \multicolumn{2}{|l|}{$\begin{array}{l}\text { Тамоксифен 2-3 года } \rightarrow \text { ингибиторы } \\
\text { ароматазы 2-3 года (суммарно - } 5 \text { лет) }\end{array}$} \\
\hline Ингибиторы ароматазы 7 лет & $\begin{array}{l}\text { При наличии по крайней мере одного фактора неблагоприят- } \\
\text { ного прогноза } 1\end{array}$ \\
\hline Тамоксифен 10 лет & $\begin{array}{l}\text { При наличии по крайней мере одного фактора неблагоприят- } \\
\text { ного прогноза } 1\end{array}$ \\
\hline
\end{tabular}




\begin{tabular}{|l|l|}
\hline Режимы гормонотерапии & Примечания \\
\hline $\begin{array}{l}\text { Тамоксифен } 5 \text { лет } \rightarrow \text { ингибиторы } \\
\text { ароматазы 2 года }\end{array}$ & $\begin{array}{l}\text { При наличии по крайней мере одного фактора неблагоприят- } \\
\text { ного прогноза }{ }^{1}\end{array}$ \\
\hline
\end{tabular}

1 К факторам неблагоприятного прогноза относятся T3-4, N+, G3, гиперэкспрессия/амплификация HER2, высокий Кі67, выраженная лимфоваскулярная инвазия.

2 Рекомендуемая продолжительность овариальной супрессии составляет 5 лет.

3 Овариальная супрессия необходима в течение всего срока приема ингибиторов ароматазы.

4 При промежуточном прогнозе (T2NO и G2) в случае назначения овариальной супрессии (в сочетании с тамоксифеном или ингибиторами ароматазы) возможен отказ от адъювантной XT.

Терапия ингибиторами ароматазы ассоциируется с меньшей частотой тромбоэмболических осложнений и рака эндометрия и с большей частотой остеопороза (и связанных с ним переломов костей) и осложнений со стороны сердечнососудистой системы по сравнению с тамоксифеном. Ингибиторы ароматазы третьего поколения (летрозол, анастрозол, эксеместан) равно эффективны и сопоставимы по профилю токсичности.

Критериями постменопаузы являются:

- билатеральная овариэктомия;

- возраст $\geq 60$ лет;

- возраст<60 лет:

- в отсутствие XT, терапии тамоксифеном или торемифеном и овариальной супрессии: аменорея в течение $\geq 12$ мес. в сочетании с постменопаузальными уровнями ФСГ и эстрадиола;

- в процессе терапии тамоксифеном или торемифеном: постменопаузальные уровни ФСГ и эстрадиола.

Аменорея, развившаяся в процессе или по окончании XТ (нео-/адъювантной), не является достаточным признаком постменопаузы, и для оценки функции яичников необходимо определение ФСГ и эстрадиола.

Для достижения овариальной супрессии могут быть использованы следующие методы:

- лекарственный (аналоги ГРГ; см. табл. 6):

- вызывает обратимое подавление функции яичников;

- не всегда обеспечивает полное подавление функции яичников, особенно у женщин молодого возраста; для подтверждения полной овариальной супрессии необходимо определение эстрадиола в сыворотке крови 1 раз в 3 мес.; определение ФСГ в период лечения аналогами ГРГ неинформативно; прием ингибиторов ароматазы следует начинать через 6-8 нед. после первого введения аналогов ГРГ;

- аналоги ГРГ рекомендуется вводить ежемесячно;

- хирургический (билатеральная овариэктомия); вызывает необратимое подавление функции яичников;

- лучевой; вызывает необратимое подавление функции яичников. 
У молодых женщин, особенно не завершивших репродуктивную функцию, для достижения овариальной супрессии рекомендуется назначение аналогов ГРГ, подавляющих функцию яичников обратимо.

\subsubsection{6. Остеомодифицирующие препараты в адъювантной терапии}

Больным гормонозависимым РМЖ в постменопаузе (в т. ч. получающим овариальную супрессию) с целью профилактики остеопороза и снижения риска рецидива болезни рекомендуется назначить:

- бисфосфонаты (золедронат 4 мг в/в 1 раз в 6 мес.) в течение 2-3 лет;

- колекальциферол 400-800 МЕ/ сут. внутрь ежедневно + кальция карбонат 500-1000 мг/сут. внутрь ежедневно длительно;

- контроль минеральной плотности костей (денситометрия) 1 раз в год.

\subsubsection{7. Неоадъювантная лекарственная терапия первично операбельного рака молочной железы}

Очередность лекарственного и хирургического лечения не влияет на безрецидивную и общую выживаемость. Неоадъювантная лекарственная терапия первично операбельного РМЖ позволяет:

1) выполнить органосохраняющую операцию и/или улучшить косметический эффект;

2) оценить эффект лекарственной терапии и своевременно прекратить ее в случае прогрессирования (с выполнением хирургического лечения);

3) оценить выраженность патоморфологического ответа и назначить дополнительную адъювантную терапию.

Неоадъювантная лекарственная (химиотерапия \pm анти-HER2) терапия может быть рекомендована при соблюдении следующих условий:

- доказанный инвазивный первично операбельный РМЖ (T0-1N1M0, T2N0M0, T2N1M0, T3NOMO, T3N1M0);

- тройной негативный фенотип или HER2-положительный статус с целью выполнения органосохраняющей операции, а также определения прогноза и проведения дополнительной адъювантной терапии в случае наличия резидуальной опухоли;

- может быть рассмотрена у больных люминальным В раком высокого риска (G3, высокий Ki67) при наличии четких показаний для проведения ХТ данного объема и желании больной выполнить органосохраняющую операцию;

- наличие всех критериев, за исключением размеров опухолевого узла, свидетельствующих о возможности выполнения органосохраняющей операции;

- согласие больной на выполнение органосохраняющей операции; спациенткой должны быть обсуждены необходимость ЛТ в случае выполнения органосохраняющего лечения, а также вероятность повторной операции при обнаружении резидуальной опухоли в краях резекции; 
- абсолютные показания к проведению данного вида лекарственной терапии по результатам дооперационного обследования; при отсутствии достаточной информации (например, о размерах опухолевого узла, состоянии подмышечных лимфоузлов, наличии инвазивного компонента при внутрипротоковом РМЖ) на первом этапе рекомендуется оперативное лечение с изучением удаленной опухоли и патоморфологическим стадированием.

Перед началом неоадъювантной лекарственной терапии должно быть проведено полноценное клинико-лабораторное обследование (см. раздел 2.1. «Диагностика»), в том числе биопсия опухоли с гистологическим исследованием и определением РЭ, РП, НЕR2 и Кі67. Алгоритм лечебно-диагностических мероприятий при первично операбельном РМЖ в случае неоадъювантной лекарственной терапии представлен на рис. 3 и 4.

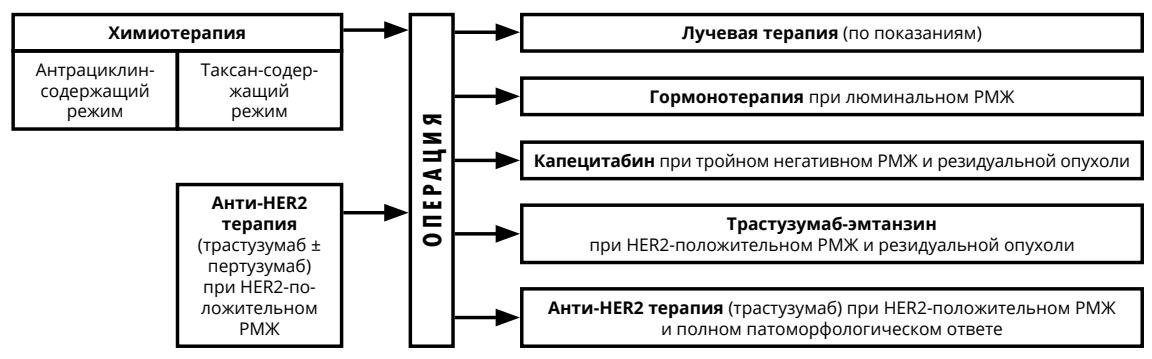

Рисунок 3. Рекомендуемая последовательность использования различных видов лечения в случае неоадъювантной терапии.

Режимы неоадъювантной лекарственной терапии представлены в табл. 8. Основные принципы неоадъювантной лекарственной терапии:

- все необходимые курсы ХТ рекомендуется проводить до операции, так как это повышает вероятность достижения полной морфологической регрессии;

- если все запланированные курсыХТ проведены до операции, адъювантная XT, как правило, не назначается; больным РMЖ с тройным негативным или HER2-положительным фенотипом, получившим неоадъювантную ХТ в стандартном объеме, при наличии инвазивной резидуальной опухоли, соответствующей RCB II-III или, при невозможности оценки по RCB, при резидуальной опухоли в регионарных лимфатических узлах (независимо от степени патоморфоза в первичной опухоли в молочной железе) или при резидуальной опухоли в молочной железе, соответствующей 0-ІІ степени лекарственного патоморофоза по Лавниковой (независимо от состояния регионарных лимфатических узлов), рекомендуется адъювантная ХТ капецитабином (при тройном негативном РМЖ) или трастузумабом-эмтанзином (при HER2-положительном РМЖ) (табл. 4, 5); 
- если по каким-либо причинам на дооперационном этапе не удалось провести все запланированные курсы XT, то недостающие курсы проводятся после операции;

- оптимальный интервал времени от начала лечения до оценки эффекта зависит от вида лечения, но не должен превышать 6-8 недель; оценку эффекта следует производить с помощью осмотра и инструментальных методов, зафиксировавших патологические изменения в молочной железе и регионарных зонах до начала лечения;

- при получении «быстрого» (в результате 2-4 курсов лечения) клинического эффекта не следует сокращать объем лечения менее чем до 6-8 курсов.

- после завершения неоадъювантной терапии, при отсутствии клинических признаков прогрессирования болезни, оценку эффекта следует производить с помощью осмотра и инструментальных методов, зафиксировавших патологические изменения в молочной железе и регионарных зонах до начала лечения.

При отсутствии достаточных материальных ресурсов, гарантирующих проведение оптимальной неоадъювантной лекарственной терапии (антрациклины, таксаны, трастузумаб, пертузумаб, колониестимулирующие факторы, если таковые показаны), целесообразно на первом этапе выполнить хирургическое лечение. Неоадъювантная ХТ при первично операбельном люминальном А варианте РМЖ не рекомендуется. 

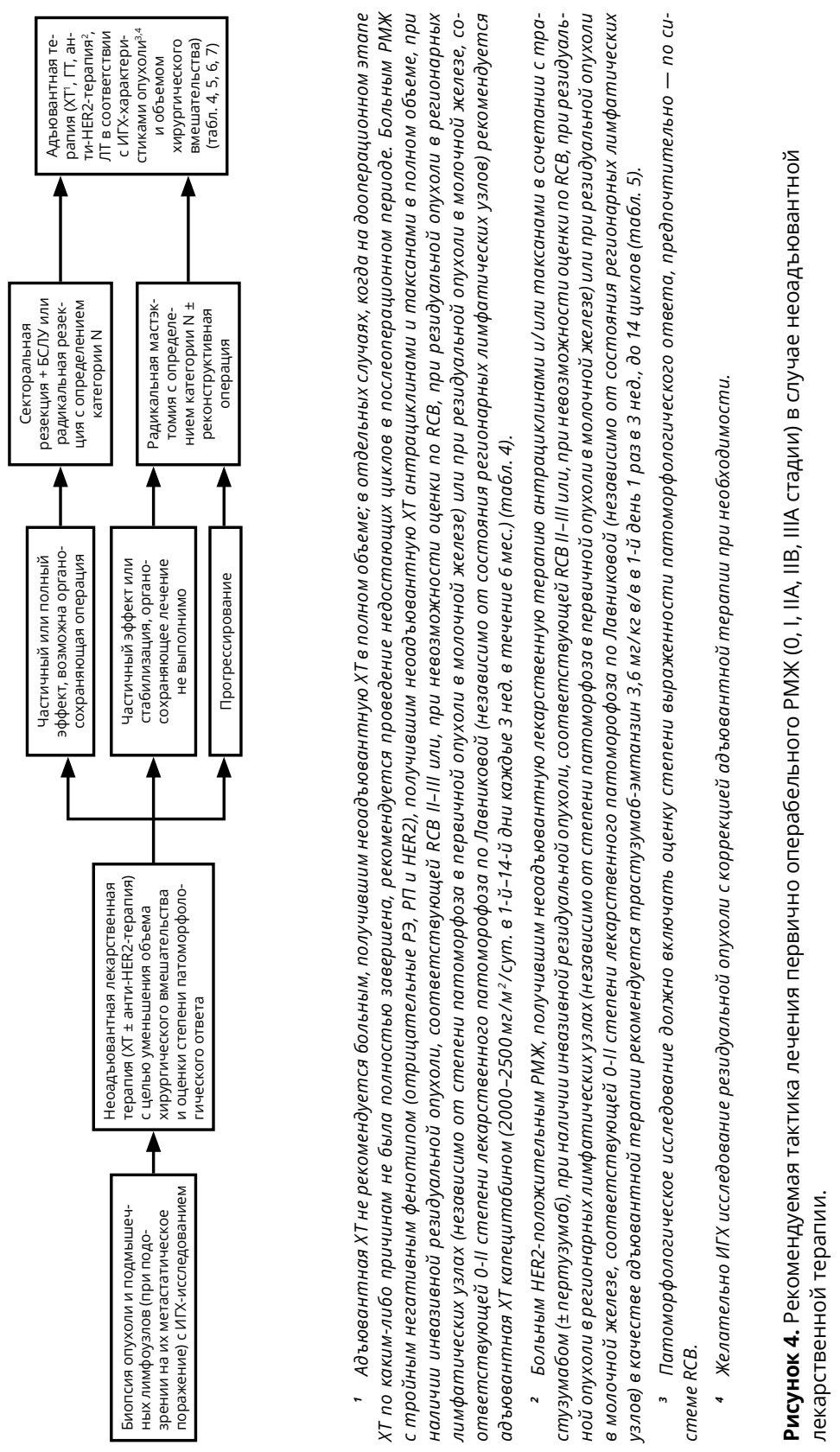
Таблица 8. Рекомендуемые режимы неоадъювантной лекарственной терапии рака молочной железы

\begin{tabular}{|c|c|}
\hline \multicolumn{2}{|l|}{ HER2-отрицательный } \\
\hline $\mathrm{AC} \times 4 \rightarrow \mathrm{D} \times 4^{1}$ & $\begin{array}{l}\text { АС (доксорубицин } 60 \text { мг/м² в/в в 1-й день + циклофосфамид } \\
600 \text { мг/м² в/в в 1-й день) } 1 \text { раз в } 3 \text { нед., } 4 \text { цикла } \rightarrow \text { доцетаксел } \\
75 \text { мг/м² в/в в 1-й день } 1 \text { раз в } 3 \text { нед., } 4 \text { цикла }\end{array}$ \\
\hline $\mathrm{AC} \times 4 \rightarrow \mathrm{P} \times 12^{1,10}$ & $\begin{array}{l}\text { АС (доксорубицин } 60 \text { мг/м² в/в в 1-й день + циклофосфамид } \\
600 \text { мг/м² в/в в 1-й день) } 1 \text { раз в } 3 \text { нед., } 4 \text { цикла } \rightarrow \text { паклитаксел } \\
80 \text { мг/м² в/в еженедельно, } 12 \text { введений }\end{array}$ \\
\hline$A C \times 4 \rightarrow P \times 4^{1,2,3}$ & $\begin{array}{l}\text { АС (доксорубицин } 60 \text { мг/м² в/в в 1-й день + циклофосфамид } \\
600 \text { мг/м² в/в в 1-й день) } 1 \text { раз в } 2 \text { нед., } 4 \text { цикла } \rightarrow \text { паклитаксел } \\
175 \text { мг/м² в/в в 1-й день } 1 \text { раз в } 2 \text { нед., } 4 \text { цикла }\end{array}$ \\
\hline $\mathrm{AC} \times 4 \rightarrow \mathrm{P} \times 12^{1,2,3,10}$ & $\begin{array}{l}\text { АС (доксорубицин } 60 \text { мг/м² в/в в 1-й день + циклофосфамид } \\
600 \text { мг/м² в/в в 1-й день) } 1 \text { раз в } 2 \text { нед., } 4 \text { цикла } \rightarrow \text { паклитаксел } \\
80 \text { мг/м² в/в еженедельно, } 12 \text { введений }\end{array}$ \\
\hline $\begin{array}{l}\text { AC } \times 4 \rightarrow \\
(P+\text { карбо }) \times 12^{1,2,3,4,10}\end{array}$ & $\begin{array}{l}\text { АС (доксорубицин } 60 \text { мг/м² в/в в 1-й день + циклофосфамид } \\
600 \text { мг/м² в/в в 1-й день) } 1 \text { раз в } 2 \text { или } 3 \text { нед., } 4 \text { цикла } \rightarrow \text { паклитаксел } \\
80 \text { мг/м² в/в еженедельно } 12 \text { введений + карбоплатин AUС - } 6 \text { в/в } 1 \text { раз } \\
\text { в } 3 \text { нед. } 4 \text { цикла }\end{array}$ \\
\hline \multicolumn{2}{|l|}{ HER2-положительный } \\
\hline $\begin{array}{l}\text { AC } \times 4 \rightarrow \\
(D+\text { трастузумаб }) \times 4^{1,6,7,8}\end{array}$ & $\begin{array}{l}\text { АС (доксорубицин } 60 \text { мг/м² в/в в 1-й день + циклофосфамид } \\
600 \text { мг/м² в/в в 1-й день) } 1 \text { раз в } 3 \text { нед., } 4 \text { курса } \rightarrow \text { доцетаксел } \\
75 \text { мг/м² в/в в 1-й день } 1 \text { раз в } 3 \text { нед. + трастузумаб } 6 \text { мг/кг (нагрузочная } \\
\text { доза } 8 \text { мг/кг) в/в в 1-й день } 1 \text { раз в } 3 \text { нед., } 4 \text { цикла }\end{array}$ \\
\hline $\begin{array}{l}\text { АC } \times 4 \rightarrow \\
(P+\text { трастузумаб }) \times 12^{1,6,7,8,10}\end{array}$ & $\begin{array}{l}\text { АС (доксорубицин } 60 \text { мг/м² в/в в 1-й день + циклофосфамид } \\
600 \text { мг/м² в/в в 1-й день) } 1 \text { раз в } 3 \text { нед., } 4 \text { курса } \rightarrow \text { паклитаксел } \\
80 \text { мг/м² в/в еженедельно, } 12 \text { введений + трастузумаб } 2 \text { мг/кг (нагрузоч- } \\
\text { ная доза } 4 \text { мг/кг) в/в еженедельно } 12 \text { введений }\end{array}$ \\
\hline $\begin{array}{l}\text { АC } \times 4 \rightarrow \\
(P+\text { трастузумаб }) \times 4^{1,6,7,8}\end{array}$ & $\begin{array}{l}\text { АС (доксорубицин } 60 \text { мг/м² в/в в 1-й день + циклофосфамид } \\
600 \text { мг/м² в/в в 1-й день) } 1 \text { раз в } 3 \text { нед., } 4 \text { цикла } \rightarrow \text { паклитаксел } \\
175 \text { мг/м² в/в в 1-й день } 1 \text { раз в } 3 \text { нед., } 4 \text { цикла + трастузумаб } 6 \text { мг/кг } \\
\text { (нагрузочная доза } 8 \text { мг/кг) в/в в 1-й день } 1 \text { раз в } 3 \text { нед. } 4 \text { цикла }\end{array}$ \\
\hline $\mathrm{DCH} \times 6^{7,8}$ & $\begin{array}{l}\text { Доцетаксел } 75 \text { мг/м² в/в в 1-й день } 1 \text { раз в } 3 \text { нед. + карбоплатин } \\
\text { AUC-6 в/в в 1-й день } 1 \text { раз в } 3 \text { нед. + трастузумаб } 6 \text { мг/кг (нагрузочная } \\
\text { доза } 8 \text { мг/кг) в/в в 1-й день } 1 \text { раз в } 3 \text { нед., } 6 \text { циклов }\end{array}$ \\
\hline $\begin{array}{l}\text { АC } \times 4 \rightarrow \\
(P+\text { трастузумаб }) \times 12^{1,2,3,6,7,8,10}\end{array}$ & $\begin{array}{l}\text { АС (доксорубицин } 60 \text { мг/м² в/в в 1-й день + циклофосфамид } \\
600 \text { мг/м² в/в в 1-й день) } 1 \text { раз в } 2 \text { нед., } 4 \text { курса } \rightarrow \text { паклитаксел } \\
80 \text { мг/м² в/в еженедельно, } 12 \text { введений + трастузумаб } 2 \text { мг/кг (нагрузоч- } \\
\text { ная доза } 4 \text { мг/кг) в/в еженедельно } 12 \text { введений }\end{array}$ \\
\hline $\begin{array}{l}\text { АC } \times 4 \rightarrow \\
(P+\text { трастузума6 }) \times 41,2,3,6,7,8\end{array}$ & $\begin{array}{l}\text { АС (доксорубицин } 60 \text { мг/м² в/в в 1-й день + циклофосфамид } \\
600 \text { мг/м² в/в в 1-й день) } 1 \text { раз в } 2 \text { нед., } 4 \text { цикла } \rightarrow \text { паклитаксел } \\
175 \text { мг/м² в/в в 1-й день } 1 \text { раз в } 2 \text { нед., } 4 \text { цикла + трастузума6 } 6 \text { мг/кг } \\
\text { (нагрузочная доза } 8 \text { мг/кг) в/в еженедельно, } 8 \text { введений }\end{array}$ \\
\hline $\begin{array}{l}\text { AC } \times 4 \rightarrow(\mathrm{D}+\text { трастузумаб + } \\
\text { пертузумаб) } \times 4^{1,2,3,6,7,8,9}\end{array}$ & $\begin{array}{l}\text { АС (доксорубицин } 60 \text { мг/м² в/ в в 1-й день + циклофосфамид } \\
600 \text { мг/м² в/в в 1-й день) } 1 \text { раз в 2-3 нед., } 4 \text { цикла } \rightarrow \text { доцетаксел } \\
75 \text { мг/м² в/в в 1-й день } 1 \text { раз в } 3 \text { нед. + трастузумаб } 6 \text { мг/кг (нагрузочная } \\
\text { доза } 8 \text { мг/кг) в/в в 1-й день } 1 \text { раз в } 3 \text { нед. + пертузумаб } 420 \text { мг (нагрузоч- } \\
\text { ная доза } 840 \text { мг) в/в в 1-й день } 1 \text { раз в } 3 \text { нед., } 4 \text { цикла }\end{array}$ \\
\hline$(\mathrm{DCH}+$ пертузумаб) × 67,8,9 & $\begin{array}{l}\text { Доцетаксел } 75 \text { мг/м² в/в в 1-й день } 1 \text { раз в } 3 \text { нед. + карбоплатин } \\
\text { AUC-6 в/в в 1-й день } 1 \text { раз в } 3 \text { нед. + трастузумаб } 6 \text { мг/кг (нагрузочная } \\
\text { доза } 8 \text { мг/кг) в/в в 1-й день } 1 \text { раз в } 3 \text { нед. + пертузумаб } 420 \text { мг (нагрузоч- } \\
\text { ная доза } 840 \text { мг) в/в в 1-й день } 1 \text { раз в } 3 \text { нед., } 6 \text { циклов }\end{array}$ \\
\hline
\end{tabular}


1 Доксорубицин может быть заменен на эпирубицин в курсовой дозе 90-100 мг/м² (режим ЕС).

2 Режим с уплотненным введением химиопрепаратов следует рассмотреть при быстро пролиферирующих (с высоким Кі67) вариантах РМЖ.

3 Рекомендуется профилактическое назначение Г-КСФ (филграстим 5 мкг/кг n/к через 24-72 часа после окончания введения химиопрепаратов и до восттановления нормального числа нейтрофилов после надира или пэгфилграстим 6 мг или эмпэгфилграстим 7,5 мг n/к, не менее чем через 24 часа после окончания и не ранее чем за 14 дней до введения химиопрепаратов).

4 Режимы с включением производных платины могут быть использованы при тройном негативном феноmune.

5 При противопоказаниях к назначению антрациклинов и таксанов.

6 Не рекомендуется одновременное введение антрациклинов (доксорубицина, эпирубицина) и антиHER2 препаратов (трастузумаба, пертузумаба) ввиду высокого риска кардиотоксичности; до и в прочессе терапии антрациклинами и/или трастузумабом необходим контроль ФВлж с помощью ЭхоКГ с частотой 1 раз в 3 мес. (или чаще при наличии показаний).

7 Введение анти-HER2 препаратов (трастузумаба, пертузумаба) должно начинаться одновременно с безантрациклиновым таксан-содержащим режимом.

8 Возможно использование лекарственной формы трастузумаба для $n /$ кведения в дозе 600 мг/5 мл (независимо от массы тела пациента) 1 раз в 3 нед.; нагрузочная доза не требуется.

9 Режим может быть использован в качестве неоадъювантной терапии при опухолях $\geq T 2$ или N+.

10 При использовании еженедельных введений паклитаксела объем стандартной премедикации может быть сокращен (на усмотрение лечащего врача) и проводиться по схеме: 1-2-й курсы - дексаметазон 10 мг в/м или внутрь за 12 и 6 часов до введения паклитаксела, блокаторы рецепторов Н1 (дифенгидрамин 50 мг или эквивалентные дозы аналогов) в/в струйно за 30-60 мин. до введения паклитаксела, блокаторы рецепторов Н2 (фамотидин 50 мг или эквивалентные дозы аналогов) в/в струйно за 30-60 мин. до введения паклитаксела. При отсутствии реакций гиперчувствительности на первых двух курсах в дальнейшем возможно введение дексаметазона 8 мг в/в за 30-60 мин. до введения паклитаксела, а введение блокаторов Н1/H2 гистаминовых рецепторов - только в случае предшествовавших реакций гиперчувствительности. Введение паклитаксела может проводиться при $А Ч Н \geq 1,0 \times 10^{9} / л$ и количестве тромбочитов $\geq 100,0 \times 10^{9} / л$.

\subsection{2. Местнораспространенный первично не операбельный инвазивный рак молочной железы (стадии IIIA (кроме T3NIMO), IIIB и IIIC, В т. ч. инфильтративно-отечная форма)}

Рак молочной железы стадий IIIA (кроме T3N1M0), IIIB и IIIC, В т. ч. инфильтративно-отечная форма является первично не операбельным и требует лекарственной терапии в качестве первого этапа лечения. Основной целью неоадъювантной лекарственной терапии является уменьшение размеров опухоли с целью достижения операбельного состояния. Локальное лечение (хирургическое, лучевое) на первом этапе не показано. Тактика лечения местнораспространенного первично не операбельного РМЖ представлена на рис. 3, 5.

Первичное обследование проводится в стандартном объеме (см. раздел 2.1), включая дополнительные диагностические методы, позволяющие исключить наличие отдаленных метастазов, вероятность которых у данной категории больных значительно выше, чем у больных с первично операбельным процессом (см. раздел 2.1. «Диагностика»).

Неоадъювантная лекарственная терапия проводится по тем же правилам, что и при первично операбельном РМЖ (табл. 8). Больным в менопаузе с люминальным подтипом РМЖ может быть рекомендована неоадъювантная ГТ, которую следует проводить в течение 4-8 мес. или до достижения макси- 
мального эффекта. Препаратами выбора для неоадъювантной ГТ являются ингибиторы ароматазы.

Алгоритм назначения адъювантной лекарственной терапии аналогичен таковому при первично операбельном РМЖ:

- адъювантная XТ, как правило, не назначается, если все запланированные курсы проведены до операции; больным РМЖ с тройным негативным и HER2-положительным фенотипом, получившим неоадъювантную ХТ антрациклинами и таксанами в полном объеме, при наличии резидуальной опухоли, соответствующей RCB II-III, может быть назначена дополнительная адъювантная XТ капецитабином (при тройном негативном РМЖ) или трастузумабом-эмтанзином (при HER2-положительном PMЖ) (табл. 4, 5);

- адъювантная гормонотерапия назначается всем больным с гормонозависимыми опухолями (см. раздел 2.2.1.4., табл. 6, 7);

- адъювантная анти-HER2-терапия назначается всем больным при HER2-положительных опухолях.

\subsection{3. Наблюдение после первичного лечения раннего и местно-распространенного рака молочной железы}

Основной целью наблюдения является максимально ранее выявление местных рецидивов и рака контралатеральной молочной железы, так как это обеспечивает возможность радикального лечения. Наблюдение после первичного лечения предполагает осмотр и выяснение жалоб от 1 до 4 раз в год (в зависимости от конкретной клинической ситуации) в течение первых 5 лет, далее - ежегодно.

Рекомендуется ежегодно выполнять двухстороннюю (в случае органосохраняющей операции) или контралатеральную маммографию в сочетании с УЗИ регионарных зон и области послеоперационного рубца. При отсутствии жалоб и симптомов, подозрительных в отношении прогрессирования болезни, лабораторное и инструментальное обследование (определение опухолевых маркеров, R-графическое, УзИ, радиоизотопное, КТ, МРТ, ПЭТ/КТ) не рекомендуется.

Женщины с неудаленной маткой, получающие адъювантно тамоксифен, должны осматриваться гинекологом ежегодно. Любые патологические состояния, подозрительные в отношении рака эндометрия, подлежат максимально быстрой уточняющей диагностике. Рутинное (в отсутствие жалоб) выполнение УзИ и биопсии эндометрия (раздельное диагностическое выскабливание) не рекомендуется.

Следует обращать особое внимание на отдаленные нежелательные эффекты, в частности остеопороз, особенно у женщин, длительно получающих ингибиторы ароматазы, а также достигших ранней менопаузы в результате противоопухолевой терапии. Этой категории пациенток показано ежегодное выполнение денситометрии и профилактическое назначение препаратов кальция, витамина D и бисфосфонатов (см. раздел 2.2.1.5.). 


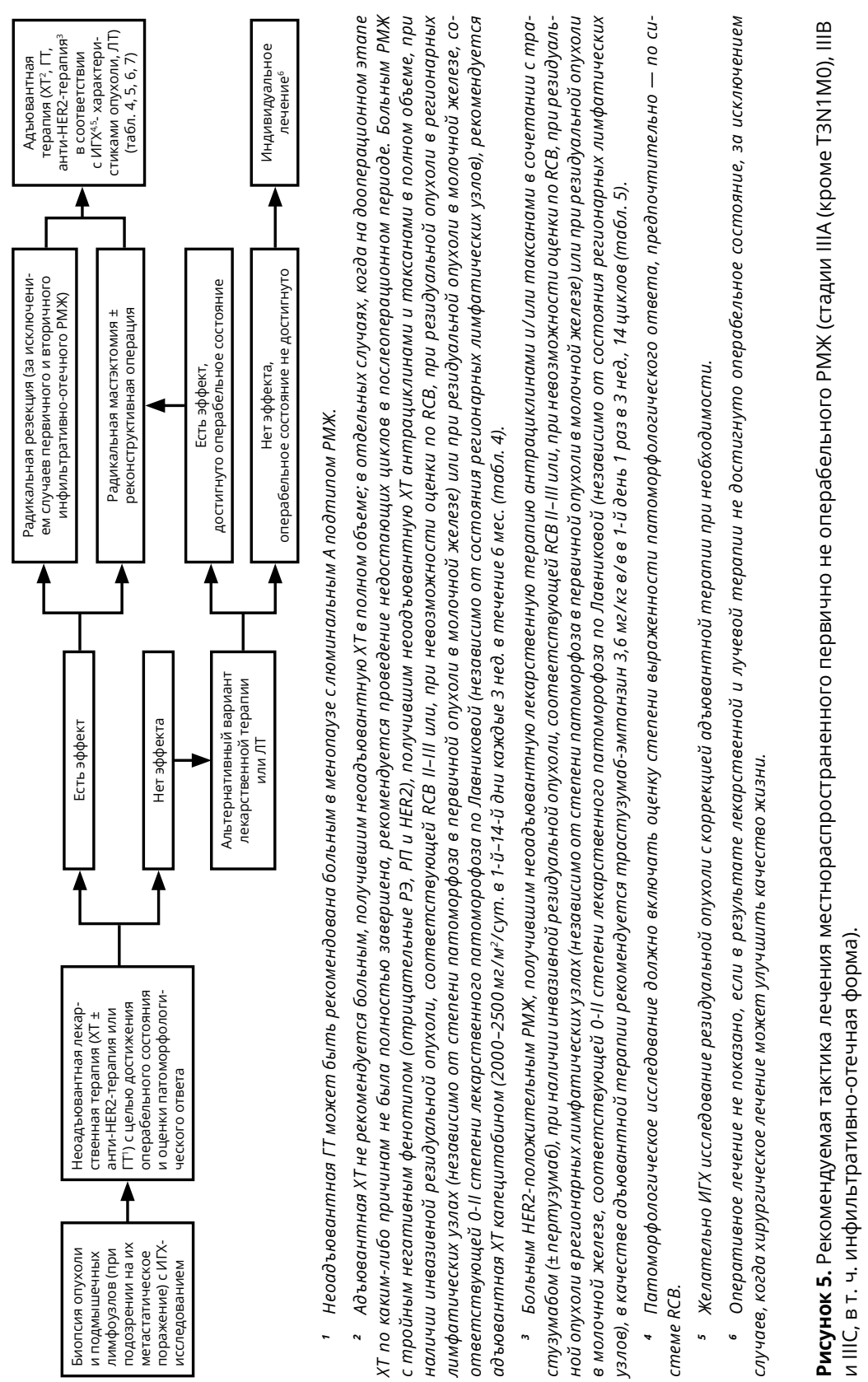


Следует информировать пациенток о пользе здорового образа жизни, включающего рациональную диету, достижение и поддержание идеальной массы тела, ведение активного образа жизни.

\section{3. РЕЦИДИВНЫЙ И МЕТАСТАТИЧЕСКИЙ РАК МОЛОЧНОЙ ЖЕЛЕЗЫ}

\section{1. Диагностика}

При наличии клинических подозрений необходимо подтверждение диагноза с помощью инструментальных методов обследования с выполнением общего и биохимического анализов крови (см. раздел 2.1. «Диагностика»). Морфологическое (гистологическое или цитологическое) исследование первичной опухоли с определением РЭ, РП, НЕR2 и Кi67 должно выполняться во всех случаях впервые выявленного метастатического РМЖ, а также во всех возможных случаях в метастатических и рецидивных очагах при прогрессировании после первичного лечения раннего и местно-распространенного РМЖ.

Всем больным показано генетическое тестирование с определением герминальных мутаций BRCA1 / 2 (если не проводилось ранее) для решения вопроса об объеме возможного хирургического лечения (при рецидивном РМЖ) и назначении ингибиторов PARP (при метастатическом HER2-отрицательном PMЖ).

У больных метастатическим гормонозависимым HER2-негативным PMЖ целесообразно определение мутаций в гене PIK3СА для решения вопроса о назначении алпелисиба в комбинации с фулвестрантом (табл. 9).

у больных метастатическим тройным негативным РМж, не получавших лечение по поводу метастатической болезни, целесообразно определение с помощью теста Ventana SP142 уровня экспрессии PD-L1 на иммунокомпетентных клетках (первичной опухоли или, предпочтительно, биопсийного материала из метастатического очага) для решения вопроса о назначения «паклитаксела + альбумина» в комбинации с атезолизумабом (табл. 10).

\section{2. Лечение изолированных местных рецидивов}

Терапия изолированных местных рецидивов имеет целью излечение и должна проводиться аналогично лечению первичной опухоли с подключением необходимых методов диагностики (клиническое обследование с целью уточнения степени распространения болезни, определение РЭ, РП, HER2 и Кi67 в рецидивной опухоли; см. раздел 2.1 «Диагностика») и лечения (см. раздел 2.2 «Лечение»). После удаления изолированного местного рецидива рекомендуется назначение лекарственной терапии, выбор которой должен быть индивидуальным и учитывать иммунофенотип первичной и рецидивной опухоли, предшествующее нео-/адъювантное лечение и срок ремиссии, общее состояние больного, в т. ч. остаточные явления токсичности ранее проведенного лечения. Рекомендуется:

- при тройном негативном фенотипе: адъювантная ХT (необходимо учесть суммарную дозу антрациклинов, если они назначались ранее) (табл. 4); 
- при люминальном HER2-отрицательном фенотипе: только адъювантная ГT; выбор препарата определяется предшествующей ГТ, если таковая проводилась, и функцией яичников (табл. 7);

- при HER2-положительном фенотипе: XT + анти-HER2-терапия \pm ГТ (в зависимости от уровня экспрессии РЭ и РП) (табл. 5).

Следует рассмотреть назначение лт во всех случаях, когда она не проводилась ранее, а также при наличии возможности дополнительного безопасного облучения пораженной зоны.

Наблюдение после лечения по поводу местных рецидивов аналогично таковому при первичном РМЖ.

\section{3. Лечение метастатического рака молочной железы}

Лечение метастатической болезни является паллиативным и направлено на улучшение качества жизни и увеличение ее продолжительности. Основным методом лечения метастатической болезни является лекарственная терапия. Единого стандарта лечения метастатического РМЖ не существует. Выбор варианта лекарственной терапии осуществляется с учетом биологических маркеров (экспрессия РЭ и PП, HER2, Ki67, мутации PIK3CA, экспрессия PD-L1, герминальные мутации BRCA1/2) и клинико-анамнестических особенностей больного. До начала терапии необходимо клинико-лабораторное обследование для определения степени распространенности заболевания и оценки функции внутренних органов (см. раздел 2.1. «Диагностика»).

Системная терапия при необходимости может дополняться локальными видами лечения (лучевым и / или хирургическим).

При метастазах в костях показано назначение ОМА:

- золедронат 4 мг в/в 1 раз в 4-12 нед.

- памидронат 90 мг в/в 1 раз в 3-4 нед.

- ибандронат 6 мг в/в 1 раз в 3-4 нед. или 50 мг/сут. внутрь ежедневно

- клодронат 1500 мг в/в 1 раз в 4 нед. или по 300 мг в/в в течение 5-7 дней каждые 4 нед. или 1600 мг внутрь ежедневно

- деносумаб 120 мг п/к 1 раз в 4 нед.

Подробнее - см. раздел «Использование остеомодифицирующих агентов для профилактики и лечения патологии костной ткани при злокачественных новообразованиях».

\subsection{1. Лекарственная терапия метастатического гормонозависимого рака молочной железы (гормонотерапия)}

Методом выбора терапии гормонозависимого (люминального) РМЖ является ГТ даже при наличии висцеральных метастазов. Исключение составляют:

- быстропрогрессирующие варианты РМЖ, сопровождающиеся висцеральным кризом, в том числе развившимся в процессе предшествующих линий Гт; 
- иные клинические ситуации, требующие максимально быстрого достижения противоопухолевого эффекта;

- случаи исчерпанности возможностей ГТ.

Признаками висцерального криза являются:

- множественное метастатическое поражение внутренних органов;

- клинические и /или лабораторные признаки нарушения функции внутренних органов, создающие угрозу жизни пациента и требующие быстрого достижения противоопухолевого эффекта.

После завершения XT, назначенной в связи с висцеральным кризом, возможно назначение «поддерживающей» гормонотерапии с учетом предшествующих линий.

Алгоритм назначения лекарственной терапии при метастатическом гормонозависимом РМЖ представлен на рис. 6.

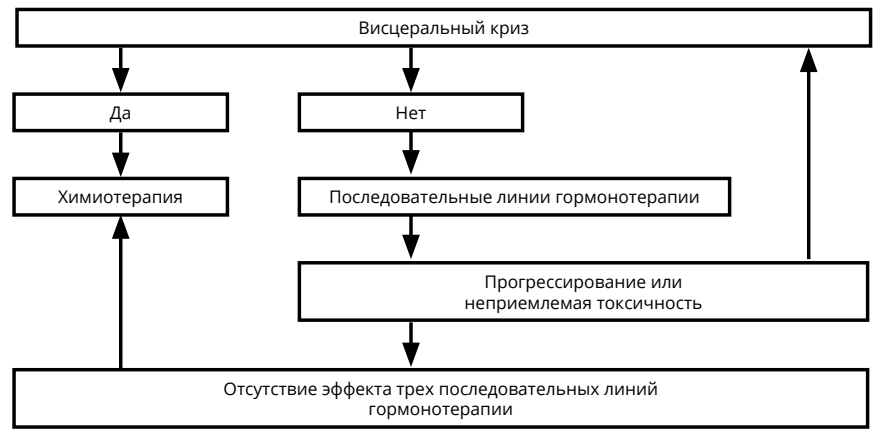

Рисунок 6. Рекомендуемый алгоритм назначения лекарственной терапии при метастатическом гормонозависимом раке молочной железы.

ГТ одной линии проводится до прогрессирования болезни (данные осмотра и инструментального обследования или появление/усиление симптомов, связанных с опухолевым ростом) или признаков неприемлемой токсичности. В отсутствие признаков висцерального криза рекомендуется последовательное назначение всех возможных линий ГТ. Неэффективность трех последовательных линий ГТ свидетельствует об устойчивости к данному виду лечения и необходимости назначения ХТ. При выборе варианта ГТ следует учитывать функцию яичников (пре- или постменопауза), предшествующую ГТ и ее эффективность, сопутствующую патологию. Больным с сохранной функцией яичников рекомендуется выполнить овариальную супрессию любым доступным способом (см. раздел 2.2.1.4.) и назначить ГТ, рекомендованную больным в постменопаузе (рис. 7, табл. 9). В отдельных случаях (например, при отказе больной от овариальной супрессии) могут быть назначены селективные модуляторы РЭ. Одновременное использование ХT и ГТ не рекомендуется. 


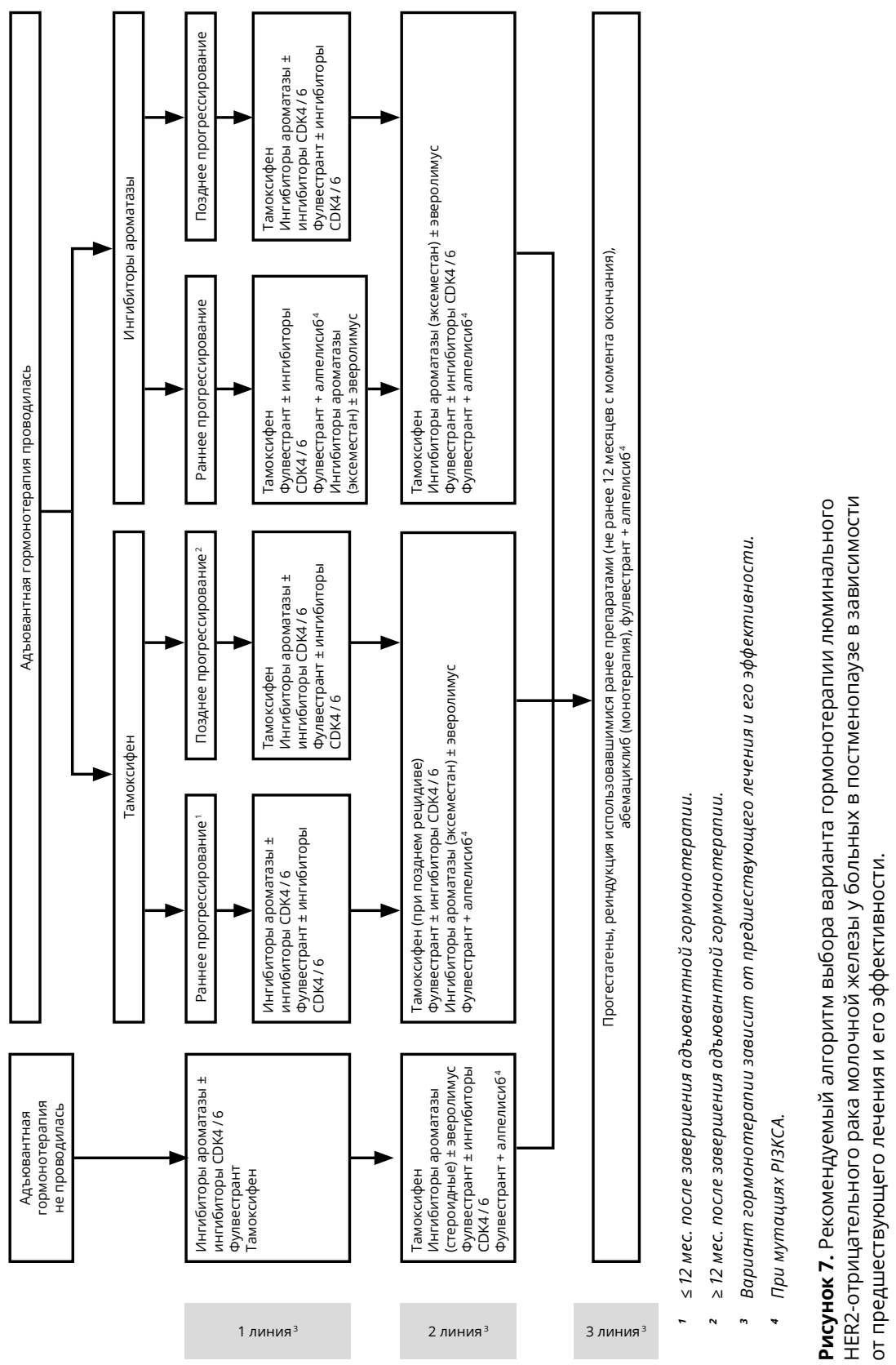


Таблица 9. Рекомендуемые режимы лекарственной терапии метастатического гормонозависимого HER2-отрицательного рака молочной железы (гормонотерапия)

\begin{tabular}{|c|c|}
\hline Аналоги ГРГ ${ }^{1}$ & $\begin{array}{l}\text { Гозерелин 3,6 мг п/к } 1 \text { раз в } 28 \text { дней } \\
\text { Бусерелин 3,75 мг в/ м } 1 \text { раз в } 28 \text { дней } \\
\text { Лейпрорелин 3,75 мг в/ м } 1 \text { раз в } 28 \text { дней } \\
\text { Любой из препаратов назначается на весь период ГТ }\end{array}$ \\
\hline $\begin{array}{l}\text { Ингибиторы ароматазы } \\
\text { третьего поколения } \\
+ \text { ингибиторы CDK4/6 } 6^{3,4,8}\end{array}$ & $\begin{array}{l}\text { Анастрозол } 1 \text { мг/сут. или летрозол 2,5 мг/сут. или эксеместан } \\
25 \text { мг/сут. внутрь ежедневно + палбоциклиб } 125 \text { мг/сут. или рибоци- } \\
\text { клиб } 600 \text { мг/сут. внутрь в 1-21-й дни, интервал } 1 \text { нед. (длительность } \\
\text { цикла } 28 \text { дней) или абемациклиб по } 300 \text { мг/сут. внутрь (в два приема) } \\
\text { ежедневно до прогрессирования или неприемлемой токсичности }\end{array}$ \\
\hline $\begin{array}{l}\text { Фулвестрант } \\
+ \text { ингибиторы CDK4/6 }\end{array}$ & $\begin{array}{l}\text { Фулвестрант } 500 \text { мг в/м } 1 \text { раз в мес. (в первый месяц - по } 500 \text { мг } \\
\text { в 1-й и 15-й дни) + палбоциклиб } 125 \text { мг/сут. или рибоциклиб } \\
600 \text { мг/сут. внутрь в 1-21-й дни, интервал } 1 \text { нед. (длительность цикла } \\
28 \text { дней) или абемациклиб по } 300 \text { мг/сут. внутрь (в два приема) еже- } \\
\text { дневно до прогрессирования или неприемлемой токсичности }\end{array}$ \\
\hline $\begin{array}{l}\text { Селективные модуляторы } \\
\text { рецепторов эстрогенов² }\end{array}$ & $\begin{array}{l}\text { Тамоксифен } 20 \text { мг/сут. внутрь ежедневно до прогрессирования или } \\
\text { неприемлемой токсичности } \\
\text { Торемифен } 60 \text { мг/сут. внутрь ежедневно до прогрессирования или } \\
\text { неприемлемой токсичности }\end{array}$ \\
\hline $\begin{array}{l}\text { Антагонисты рецепторов } \\
\text { эстрогенов }\end{array}$ & $\begin{array}{l}\text { Фулвестрант } 500 \text { мг в/м } 1 \text { раз в мес. (в первый месяц - по } 500 \text { мг } \\
\text { в } 1 \text {-й и 15-й дни) (длительность цикла } 28 \text { дней) до прогрессирования } \\
\text { или неприемлемой токсичности }\end{array}$ \\
\hline $\begin{array}{l}\text { Ингибиторы ароматазы } \\
\text { третьего поколения } \\
\text { (нестероидные) }{ }^{3}\end{array}$ & $\begin{array}{l}\text { Анастрозол } 1 \text { мг/сут. внутрь ежедневно до прогрессирования или } \\
\text { неприемлемой токсичности } \\
\text { Летрозол 2,5 мг/сут. внутрь ежедневно до прогрессирования или } \\
\text { неприемлемой токсичности }\end{array}$ \\
\hline $\begin{array}{l}\text { Ингибиторы ароматазы } \\
\text { третьего поколения (стероидные) }\end{array}$ & $\begin{array}{l}\text { Эксеместан } 25 \text { мг/сут. внутрь ежедневно до прогрессирования или } \\
\text { неприемлемой токсичности }\end{array}$ \\
\hline Эксеместан + эверолимус 3,5 & $\begin{array}{l}\text { Эксеместан } 25 \text { мг/сут. внутрь ежедневно + эверолимус } 10 \text { мг/сут. внутрь } \\
\text { ежедневно до прогрессирования или неприемлемой токсичности }\end{array}$ \\
\hline Фулвестрант + алпелисиб9 & $\begin{array}{l}\text { Фулвестрант } 500 \text { мг в/м } 1 \text { раз в мес. (в первый месяц - по } 500 \text { мг } \\
\text { в 1-й и 15-й дни) + алпелисиб } 300 \text { мг/сут. внутрь ежедневно до про- } \\
\text { грессирования или неприемлемой токсичности }\end{array}$ \\
\hline Прогестагены ${ }^{3}$ & $\begin{array}{l}\text { Медроксипрогестерон 500-1000 мг/сут. внутрь ежедневно до про- } \\
\text { грессирования или неприемлемой токсичности } \\
\text { Мегестрол } 160 \text { мг/сут. внутрь ежедневно до прогрессирования или } \\
\text { неприемлемой токсичности }\end{array}$ \\
\hline Абемациклиб ${ }^{6,7}$ & $\begin{array}{l}\text { Абемациклиб } 400 \text { мг/сут. внутрь (в два приема) ежедневно до про- } \\
\text { грессирования или неприемлемой токсичности }\end{array}$ \\
\hline
\end{tabular}

1 Только для больных с сохранной функцией яичников при необходимости овариальной супрессии; назначаются в сочетании с другими средствами ГТ (селективными модуляторами эстрогеновых рецепторов, антагонистами рецепторов эстрогенов, ингибиторами ароматазы, прогестагенами); ГРГ рекомендуется вводить 1 раз в 28 дней.

2 Для больных в пременопаузе и менопаузе; определение мутаций гена CYP2D6 для решения вопроса о назначении тамоксифена в рутинной практике не рекомендуется; следует избегать совместного назначения тамоксифена и ингибиторов CYP2D6.

3 Только для больных в менопаузе; у больных с сохранной функцией яичников требуется овариальная супрессия (назначение аналогов ГРГ или овариэктомия).

4 При развитии токсичности рекомендуется редукция доз палбоциклиба до 100 мг/сут. и 75 мг/сут., рибоциклиба - до 400 мг/сут. и 200 мг/сут., абемациклиба - до 200 мг/сут. и 100 мг/сут. внутрь (в два 
приема) (см. инструкции по применению препаратов). Не рекомендуется назначение Г-КСФ для профилактики нейтропении, связанной с применением ингибиторов CDK4/6.

5 Для больных в удовлетворительном общем состоянии, с нормальной функцией внутренних органов (в том числе при нормальном уровне глюкозы в крови) при наличии признаков резистентности к нестероидным ингибиторам ароматазы (прогрессирование в процессе адъювантной или лечебной терапии летрозолом/анастрозолом или в ближайшие 12 мес. после завершения приема этих препаратов \pm одна линия ХT); нет данных об эффективности другой линии ГТ с включением эверолимуса при прогрессировании на фоне терапии эксеместаном и эверолимусом.

6 При прогрессировании на фоне ГТ и одной или нескольких линий ХT.

7 При развитии токсичности возможна редукция дозы абемациклиба до 300 мг/сут., 200 мг/сут. и 100 мг/сут. внутрь (в два приема) (см. инструкцию по применения препарата). Не рекомендуется назначение Г-КСФ для профилактики нейтропении, связанной с применением абемациклиба.

8 Комбинации ингибиторов CDK 4/6 с ингибиторами ароматазы или фулвестрантом являются предпочтительными опциями первой и второй линий лечения, поскольку обеспечивают значимый выигрыш в безрецидивной и общей выживаемости и обладают приемлемым профилем токсичности.

9 Рекомендуется при наличии мутаций РІКЗСА больным распространенным гормонозависимым HER2-отрицательным РМЖ с погрессированием на фоне моно- или комбинированной ГТ. Алпелисиб не следует назначать больным с сахарным диабетом I типа, а также неконтролируемым диабетом II типа. До начала применения алпелисиба следует определить уровень глюкозы плазмы натощак и уровень НbА1c (гликированного гемоглобина). При уровне НbA1c > 7,0\% перед назначением терапии алпелисибом требуется консультация эндокринолога.

Больным гормонозависимым HER2-положительным РMЖ, не нуждающимся в немедленном начале XT, может быть назначена ГТ ингибиторами ароматазы, тамоксифеном или фулвестрантом в сочетании или без анти-HER2-терапии (табл. 9, 11).

\subsection{2. Лекарственная терапия метастатического HER2-негативного рака молочной железы (химиотерапия)}

XT показана следующим категориям больных:

- РМЖ с отрицательными РЭ и РП;

- люминальный РМЖ, резистентный кГТ;

- люминальный РМЖ с признаками висцерального криза.

Стандарта ХТ первой линии рецидивного и метастатического РМЖ нет. Выбор режима должен быть индивидуальным и учитывать особенности опухоли и больного, а также состав и эффективность предшествующей, в т. ч. адъювантной/неоадъювантной ХT, если таковая проводилась. Рекомендуется последовательное назначение химиопрепаратов в монотерапии. В качестве комбинированной терапии могут использоваться антрациклин-содержащие режимы, а также режимы, включающие платиновые производные. Комбинировать между собой антрациклины, таксаны, винорелбин, капецитабин не рекомендуется. В табл. 10 представлены режимы XТ, рекомендуемые при рецидивном и метастатическом РМЖ.

XT с использованием одной и той же комбинации может продолжаться до прогрессирования болезни, доказанного клинически и / или с помощью методов инструментальной диагностики, или неприемлемой/дозолимитирующей токсичности. Длительная стабилизация болезни расценивается как положительный эффект лечения и не должна являться основанием для прекращения 
или смены терапии в отсутствие серьезной токсичности. Не существует стандартных подходов к проведению второй и последующих линий ХT, равно как и каких-либо данных, свидетельствующих о преимуществах того или иного препарата или режима. Продолжение ХТ после третьей линии может обсуждаться для больных в удовлетворительном общем состоянии, ответивших на предшествующие линии ХT.

Таблица 10. Рекомендуемые режимы химиотерапии метастатического HER2-отрицательного рака молочной железы

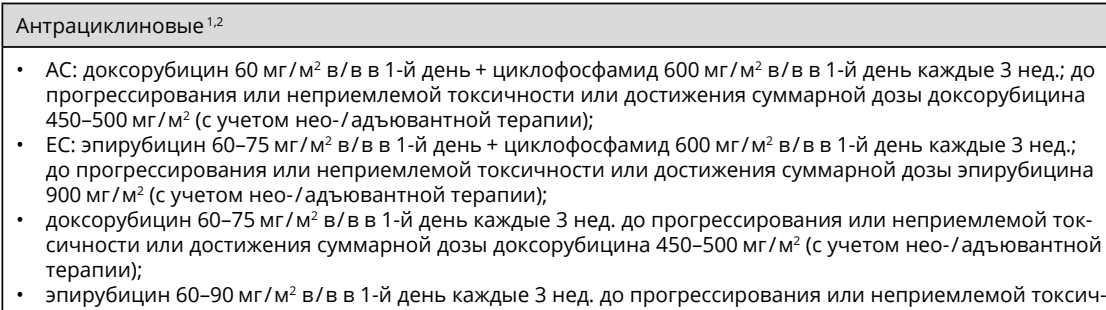

- эпирубицин 60-90 мг/м² в/в в 1-й день каждые 3 нед. до прогрессирования или неприемлемой токсич-
ности или достижения суммарной дозы эпирубицина 900 мг/м² (с учетом нео-/адъювантной терапии)

Таксановые

- паклитаксел 80 мг/м² в/в еженедельно; до прогрессирования или неприемлемой токсичности

- паклитаксел 90 мг/м² в/в 1-й, 8-й, 15-й дни каждые 4 нед; до прогрессирования или неприемлемой токсичности ${ }^{7}$

- паклитаксел 175 мг/м² в/в 1 раз в 3 нед.; до прогрессирования или неприемлемой токсичности

- доцетаксел 75 мг/м² в/в в 1-й день каждые 3 нед.; до прогрессирования или неприемлемой токсичности

- паклитаксел 80 мг/м² в/в + карбоплатин AUC2 в/в еженедельно; до прогрессирования или неприемлемой токсичности ${ }^{7}$

- (паклитаксел + альбумин) 260 мг/м² в/в в 1-й день каждые 3 нед.; до прогрессирования или неприемлемой токсичности

- паклитаксел 90 мг/м² в/в в 1-й, 8-й, 15-й дни + бевацизумаб 10 мг/кг в/в в 1-й и 15-й дни каждые 28 дней или 15 мг/кг каждые 21 день до прогрессирования или неприемлемой токсичности 4,7

- доцетаксел 75 мг/м² в/в в 1-й день каждые 3 нед. + бевацизумаб 15 мг/кг в/в в 1-й день каждые 3 нед.; до прогрессирования или неприемлемой токсичности ${ }^{4}$

Другие

- CMF: циклофосфамид 100 мг/м² внутрь в 1-й-14-й дни + метотрексат 40 мг/м² в/в в 1-й и 8-й дни + фторурацил 600 мг/м² в/в в 1-й и 8-й дни каждые 4 нед.; до прогрессирования или неприемлемой токсичности

- капецитабин 2000-2500 мг/м² внутрь в 1-й-14-й дни каждые 3 нед.; до прогрессирования или неприемлемой токсичности

- винорелбин 25 мг/м² в/в в 1-й и 8-й дни в/в каждые 3 нед; до прогрессирования или неприемлемой токсичности

- винорелбин 60 мг/м² внутрь в 1-й, 8-й, 15-й дни; с 22-го дня - 80 мг/м²1 раз в неделю;

- гемцитабин 800-1200 мг/м² в/в в 1-й, 8-й, 15-й дни каждые 4 нед.; до прогрессирования или неприемлемой токсичности

- гемцитабин 1000 мг/м² в/в в 1-й и 8-й дни + цисплатин 75 мг/м² в/в в 1-й день (или карбоплатин AUC5 в/в в 1-й день) каждые 3 нед.; до прогрессирования или неприемлемой токсичности

- цисплатин 75 мг/м² в/в в 1-й день или карбоплатин AUC6 в/в в 1-й день каждые 3 нед.; до прогрессирования или неприемлемой токсичности

- циклофосфамид 50 мг/сут. внутрь ежедневно + метотрексат по 2,5 мг внутрь 2 раза в день в 1-й и 2-й дни каждой недели (метрономный режим); до прогрессирования или неприемлемой токсичности

- иксабепилон 40 мг/м² в/в в 1-й день каждые 3 нед. (при резистентности к антрациклинам, таксанам, капецитабину); до прогрессирования или неприемлемой токсичности

- иксабепилон 40 мг/м² в/в в 1-й день каждые 3 нед. + капецитабин 2000 мг/м² внутрь в 1-й-14-й дни каждые 3 нед.; до прогрессирования или неприемлемой токсичности ${ }^{6}$

- эрибулин 1,4 мг/м² в/в в 1-й и 8-й дни каждые 3 нед.; до прогрессирования или неприемлемой токсичности

- этопозид 100 мг/сут. внутрь в 1-й-10-й дни каждые 3 нед.; до прогрессирования или неприемлемой токсичности 
Химиоиммунотерапия

- (паклитаксел + альбумин) 100 мг/м² в/в в 1-й, 8-й, 15-й дни + атезолизумаб 840 мг в/в в 1-й и 15-й дни каждые 4 нед. ${ }^{5}$

1 Суммарная доза антрациклинов с учетом всех линий терапии, включая нео-/адъювантную, не дол-

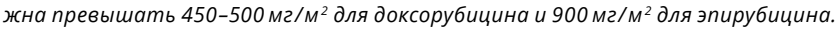

2 До и в процессе терапии антрациклинами необходим контроль ФВлж с помощью ЭхоКГ с частотой 1 раз в 3 мес. (или чаще при наличии показаний).

3 Предпочтительно еженедельное введение паклитаксела.

4 Рекомендуется при HER2-негативном РМЖ, в т. ч. при РМЖ с тройным негативным фенотипом.

5 Для больных тройным негативным РМЖ в качестве первой линии лечения при экспрессии PD-L1 на $\geq 1 \%$ иммунокомпетентных клеток (определение экспрессии PD-L1 на иммунокомпетентных клетках рекомендуется проводить с помощью теста Ventana SP142).

6 При неэффективности предшествующей терапии таксанами и антрациклинами. Не следует назначать данный режим при повышении АЛТ/АСТ более 2,5 ВГН и/или билирубина выше ВГН.

7 При использовании еженедельных введений паклитаксела объем стандартной премедикации может быть сокращен (на усмотрение лечащего врача) и проводиться по схеме: 1-2-й курсы - дексаметазон 10 мг в/м или внутрь за 12 и 6 часов до введения паклитаксела, блокаторы рецепторов Н1 (дифенгидрамин 50 мг или эквивалентные дозы аналогов) в/в струйно за 30-60 мин. до введения паклитаксела, блокаторы рецепторов Н2 (фамотидин 50 мг или эквивалентные дозы аналогов) в/в струйно за 30-60 мин. до введения паклитаксела. При отсутствии реакций гиперчувствительности на первых двух курсах в дальнейшем возможно введение дексаметазона 8 мг в/в за 30-60 мин. до введения паклитаксела, а введение блокаторов H1/H2 гистаминовых рецепторов - только в случае предшествовавиих реакций гиперчувствительности. Введение паклитаксела может проводиться при АЧН $\geq 1,0 \times 10^{9} / л$ и количестве тромбочитов $\geq 100,0 \times 10^{9} / л$.

\subsection{3. Лекарственная терапия BRCAl / 2-ассоциированного HER2-негативного метастатического рака молочной железы}

Больным BRCA1/2-ассоциированным HER2-негативным метастатическим РМЖ, получавшим ранее химиотерапию антрациклинами и таксанами с нео-/адъювантной и/или лечебной целью, рекомендуется назначение PARPингибиторов (табл. 11).

Таблица 11. Рекомендуемая терапия BRCA1/2-ассоциированного HER2-негативного метастатического рака молочной железы

Олапариб (в таблетках) по 300 мг внутрь × 2 раза в день ежедневно, цикл 28 дней

Талазопариб 1 мг/сут. внутрь ежедневно, цикл 28 дней

\subsection{4. Лекарственная терапия метастатического HER2-положительного рака молочной железы}

Больные HER2-положительным PMЖ должны получать анти-HER2-терапию в сочетании с XT или ГТ (при люминальных опухолях) или в самостоятельном виде. При первом эпизоде прогрессирования на фоне терапии трастузумабом возможно продолжение лечения этим же препаратом со сменой химио-/гормонотерапевтического компонента. Рекомендуемые режимы анти-HER2-терапии представлены в табл. 12. 
Таблица 12. Рекомендуемые режимы лекарственной терапии HER2-положительного метастатического рака молочной железы

Трастузумаб + пертузумаб + таксаны (предпочтительный режим): трастузумаб 6 мг/кг (нагрузочная доза 8 мг/кг) в/в в 1-й день 1 раз в 3 нед. + пертузумаб 420 мг (нагрузочная доза 840 мг) в/в в 1-й день 1 раз в 3 нед. + таксаны (доцетаксел 75 мг/м² в/в в 1-й день 1 раз в 3 нед. 6 курсов или паклитаксел 80 мг/м² в/в еженедельно 18 введений или паклитаксел 175 мг/м² в/в в 1-й день 1 раз в 3 нед. 6 циклов); после завершения химиотерапии таксанами - продолжение анти-HER2-терапии трастузумабом 6 мг/кг в/в в 1-день 1 раз в 3 нед. и пертузумабом 420 мг в/ в в 1-й день 1 раз в 3 нед. до прогрессирования или неприемлемой токсичности ${ }^{3,4}$

или

Трастузумаб-эмтанзин 3,6 мг/кг в/в в 1-й день 1 раз в 3 нед. до прогрессирования или неприемлемой токсичности ${ }^{5}$

или

Трастузумаб 2 мг/кг (нагрузочная доза 4 мг/кг) в/в еженедельно или 6 мг/кг (нагрузочная доза 8 мг/кг) в/ в в 1-й день каждые 3 нед. ( \pm пертузумаб 420 мг (нагрузочная доза 840 мг) в/в в 1-й день 1 раз в 3 нед., если не назначался ранее) в сочетании с одним из следующих режимов химиотерапии 1,2:

- паклитаксел 80 мг/м² в/в в 1-й, 8-й, 15-й дни каждые 4 нед. + карбоплатин AUC2 в/в в 1-й, 8-й, 15-й дни каждые 4 нед. до прогрессирования или неприемлемой токсичности ${ }^{8}$;

- паклитаксел 80 мг/м² в/в еженедельно до прогрессирования или неприемлемой токсичности;

- паклитаксел 90 мг/м² в/в в 1-й, 8-й, 15-й дни каждые 4 нед. до прогрессирования или неприемлемой токсичностив;

- доцетаксел 75 мг/м² в/в в 1-й день каждые 3 нед. до прогрессирования или неприемлемой токсичности;

- винорелбин 25 мг/м² в/в в 1-й и 8-й дни в/в каждые 3 нед. до прогрессирования или неприемлемой токсичности;

- винорелбин 60 мг/м² внутрь в 1-й, 8-й, 15-й дни; с 22-го дня - 80 мг/м² 1 раз в нед. до прогрессирования или неприемлемой токсичности;

- капецитабин 2000 мг/м² внутрь в 1-й-14-й дни каждые 3 нед. до прогрессирования или неприемлемой токсичности;

- гемцитабин 800-1200 мг/м² в/в в 1-й, 8-й, 15-й дни каждые 4 нед. до прогрессирования или неприемлемой токсичности;

- гемцитабин 1000 мг/м² в/в в 1-й и 8-й дни + цисплатин 75 мг/м² в/в в 1-й день (или карбоплатин AUC5 в/в в 1-й день) каждые 3 нед. до прогрессирования или неприемлемой токсичности;

- циклофосфамид 50 мг/сут. внутрь ежедневно + метотрексат по 2,5 мг внутрь 2 раза в день в 1-й и 2-й дни каждой недели (метрономный режим) до прогрессирования или неприемлемой токсичности;

- иксабепилон 40 мг/м² в/в в 1-й день каждые 3 нед. (при резистентности к антрациклинам, таксанам, капецитабину) до прогрессирования или неприемлемой токсичности;

- эрибулин 1,4 мг/м² в/в в 1-й и 8-й дни каждые 3 нед. до прогрессирования или неприемлемой токсичности;

- этопозид 100 мг/сут. внутрь в 1-й-10-й дни каждые 3 нед до прогрессирования или неприемлемой токсичности.

Возможно продолжение монотерапии трастузумабом без химиотерапевтического препарата в случае возникновении непереносимой токсичности последнего

или

Лапатиниб 1250 мг/сут. внутрь ежедневно + капецитабин 2000 мг/м²/сут. внутрь в 1-й-14-й дни каждые

3 нед. до прогрессирования или неприемлемой токсичности ${ }^{5}$

или

Лапатиниб 1000 мг/сут. внутрь ежедневно + трастузумаб 2 мг/кг в/в еженедельно (нагрузочная доза 4 мг/кг в/в) или 6 мг/кг (нагрузочная доза 8 мг/кг) в/в 1 раз в 3 нед. до прогрессирования или неприемлемоЙ токсичности ${ }^{5}$

\section{HER2-положительный люминальный РMж ${ }^{6,7}$}

- ингибиторы ароматазы + трастузумаб до прогрессирования или неприемлемой токсичности

- ингибиторы ароматазы + лапатиниб 1500 мг/сут. внутрь ежедневно до прогрессирования или неприемлемой токсичности

- ингибиторы ароматазы + трастузумаб + лапатиниб 1000 мг/сут. внутрь ежедневно до прогрессирования или неприемлемой токсичности

- фулвестрант + трастузумаб до прогрессирования или неприемлемой токсичности

- тамоксифен + трастузумаб до прогрессирования или неприемлемой токсичности

Если лечение было начато с режима «трастузумаб ( \pm пертузумаб) + химиотерапия», после завершения

6 курсов XТ к трастузумабу ( \pm пертузумабу) может быть добавлена Гт. 
1 Возможно использование лекарственной формы трастузумаба для $n / к$ введения в дозе 600 мг/5 мл (независимо от массы тела пациента) 1 раз в 3 нед.; нагрузочная доза не требуется.

2 До и в прочессе терапии трастузумабом необходим контроль ФВлж с помощью ЭхоКГ с частотой 1 раз в 3 мес. (или чаще при наличии показаний).

3 Увеличение количества циклов доцетаксела свыше 6 не приводит к улучшению безрецидивной и общей выживаемости.

4 Режим может быть рекомендован больным, не получавиим пертузумаб нео-/адъювантно, а также больным, получавшим пертузумаб нео-/адъювантно, если с момента завершения терапии пертузумабом до прогрессирования болезни прошло не менее 1 года.

5 Для больных, получавших трастузумаб.

6 В отсутствие признаков висцерального криза.

7 Все препараты используются в стандартных дозах и режимах; назначение ингибиторов ароматазы и фулвестранта возможно женщинам в состоянии менопаузы.

8 При использовании еженедельных введений паклитаксела объем стандартной премедикации может быть сокращен (на усмотрение лечащего врача) и проводиться по схеме: 1-2-й курсы - дексаметазон 10 мг в/м или внутрь за 12 и 6 часов до введения паклитаксела, блокаторы рецепторов Н1 (дифенгидрамин 50 мг или эквивалентные дозы аналогов) в/в струйно за 30-60 мин. до введения паклитаксела, блокаторы рецепторов Н2 (фамотидин 50 мг или эквивалентные дозы аналогов) в/в струйно за 30-60 мин. до введения паклитаксела. При отсутствии реакций гиперчувствительности на первых двух курсах в дальнейшем возможно введение дексаметазона 8 мг в/в за 30-60 мин. до введения паклитаксела, а введение блокаторов Н1/H2 гистаминовых рецепторов - только в случае предшествовавших реакций гиперчувствительности. Введение паклитаксела может проводиться при АЧН $\geq 1,0 \times 10^{9} / л$ и количестве тромбоцитов $\geq 100,0 \times 10^{9} / л$.

При прогрессировании на фоне одного из режимов лечения следует перейти на другой режим с включением анти-HER2 препаратов.

\section{4. Наблюдение за больными при метастатическом раке молочной железы}

\subsection{1. Наблюдение в процессе лечения. Оценка эффекта}

Наблюдение в процессе лечения имеет целью оценить пользу проводимой терапии (эффект) и ее возможные осложнения (токсичность) и внести необходимые коррективы (смена режима, редукция доз, отмена лечения, назначение симптоматической терапии и т. д.). Наблюдение включает периодический осмотр и оценку различных симптомов, лабораторных данных и результатов инструментального обследования.

Оценку эффекта рекомендуется проводить после каждых 2-3 мес. ГТ и каждых 2-3 курсов ХТ с помощью данных общего осмотра, выяснения жалоб, анализов крови и результатов инструментальных методов обследования, выявивших патологию на этапе первоначальной диагностики. Интервалы между обследованиями могут быть изменены в зависимости от конкретной клинической ситуации. Результаты осмотра и обследования классифицируются следующим образом:

- объективный эффект: существенное уменьшение размеров и/или количества опухолевых очагов; является показанием для продолжения проводимой терапии в отсутствие серьезной токсичности;

- стабилизация болезни: отсутствие значимых изменений размеров и количества опухолевых очагов; при удовлетворительном общем состоянии и хорошей переносимости лечение может быть продолжено; 
- прогрессирование заболевания является показанием к смене лечения. При подозрении на прогрессирование болезни по данным осмотра необходимо выполнить уточняющие обследования, в т. ч. с оценкой зон, не обследовавшихся до начала терапии. Признаками прогрессирования являются:

- появление и/или усугубление симптомов, обусловленных опухолевым ростом (например, боли или одышки);

- существенное увеличение размеров или появление новых опухолевых очагов, выявляемых при осмотре;

- ухудшение общего состояния (дифференцировать с токсичностью лечения);

- немотивированная потеря веса (дифференцировать с токсичностью лечения);

- повышение ЩФ, АЛТ, АСТ, билирубина (дифференцировать с токсичностью лечения);

- гиперкальциемия;

- появление новых и/или существенное увеличение имевшихся ранее очагов по данным объективных методов обследования; при оценке результатов рентгенографии, сканирования костей и ПЭТ следует иметь в виду, что процессы репарации метастазов в костях, начавшиеся в результате эффективной противоопухолевой терапии (в сочетании с ОМА), сопровождаются повышенным метаболизмом, что может создавать формальную картину прогрессирования за счет появления на сканограммах новых остеобластических очагов и увеличения накопления РФП в имевшихся очагах, особенно при первом оценочном исследовании.

\subsection{2. Наблюдение после окончания лечения}

Больные с метастатическим процессом должны наблюдаться с частотой, позволяющей проводить максимально возможное паллиативное лечение, обеспечивающее контроль симптомов, наилучшее качество и максимальные сроки жизни.

\section{4. ОСОБЕННОСТИ ОБСЛЕДОВАНИЯ И ЛЕЧЕНИЯ ПАЦИЕНТОК МОЛОДОГО ВОЗРАСТА}

\section{1. Рак молочной железы у пациенток детородного возраста}

Молодой возраст сам по себе не является фактором, определяющим выбор более агрессивного лечения. Тактика лекарственной терапии должна определяться общепринятыми (для больных старшей возрастной группы) характеристиками: степенью распространения опухоли, ее биологическими особенностями, сопутствующей патологией и предпочтениями больной.

Пациентки детородного возраста должны использовать надежные средства контрацепции в период лекарственной терапии и ближайшее время 
после нее. На этапе обследования следует информировать пациенток о возможном негативном влиянии лекарственного лечения на функцию яичников и фертильность. При желании пациентки в будущем иметь детей желательна консультация врача-репродуктолога для обсуждения возможных вариантов вспомогательных репродуктивных технологий (при потенциально излечимых стадиях РМЖ). Рекомендуемыми методами сохранения фертильности являются:

- криоконсервация эмбрионов;

- криоконсервация ооцитов.

Криоконсервация ткани яичников является экспериментальным методом сохранения фертильности и в рутинной практике не рекомендуется. Безопасность стимуляции суперовуляции у больных люминальным РМЖ не доказана; использование данного метода возможно только в рамках клинических исследований. Данные о возможности сохранения фертильности с помощью аналогов ГРГ противоречивы. Методы вспомогательных репродуктивных технологий могут применяться только при наличии заключения онколога.

\section{2. Рак молочной железы у беременных}

При выявлении РМЖ у беременной женщины пациентка должна быть направлена в специализированное лечебное учреждение. 